\title{
Metabolic and Immunological Effects of Intermittent Fasting on a Ketogenic Diet Containing Medium-Chain Triglycerides in Healthy Dogs
}

\author{
Y. Becca Leung ${ }^{1 *}$, Nick J. Cave ${ }^{1}$, Axel Heiser ${ }^{2}$, Patrick J. B. Edwards ${ }^{3}$, \\ A. Jonathan R. Godfrey ${ }^{3}$ and Tim Wester ${ }^{4}$
}

${ }^{1}$ School of Veterinary Science, Massey University, Palmerston North, New Zealand, ${ }^{2}$ AgResearch, Grasslands Research Centre, Hopkirk Research Institute, Palmerston North, New Zealand, ${ }^{3}$ School of Fundamental Sciences, Massey University, Palmerston North, New Zealand, ${ }^{4}$ School of Agriculture and Environment, Massey University, Palmerston North, New Zealand

\section{OPEN ACCESS}

Edited by:

Véronique Anne Lacombe, Oklahoma State University,

United States

Reviewed by:

Youssef A. Attia,

King Abdulaziz University, Saudi Arabia Christian-Alexandre Castellano,

Centre Hospitalier Universitaire de Sherbrooke, Canada

*Correspondence:

Y. Becca Leung r.leung@massey.ac.nz

Specialty section:

This article was submitted to Animal Nutrition and Metabolism,

a section of the journal

Frontiers in Veterinary Science

Received: 30 June 2019

Accepted: 06 December 2019 Published: 08 January 2020

Citation:

Leung YB, Cave NJ, Heiser A,

Edwards PJB, Godfrey AJR and

Wester T (2020) Metabolic and Immunological Effects of Intermittent

Fasting on a Ketogenic Diet

Containing Medium-Chain

Triglycerides in Healthy Dogs.

Front. Vet. Sci. 6:480

doi: 10.3389/fvets.2019.00480
In several species, intermittent fasting (IF) has been shown to have beneficial effects, including delayed aging, increased lifespan, increased insulin sensitivity, reduced ischemic tissue damage, delayed onset of neurodegenerative disease and improved neuronal repair following injury. However, the metabolic and immunological effects of IF have not been well-established in dogs. The aim of this study was to examine the effects of a $48 \mathrm{~h}$ IF regimen using a low fat and a high fat diet in healthy dogs by quantifying the metabolic, hormonal, and immunological changes. We hypothesized that IF dogs would have higher blood ketone and ghrelin concentrations, lower blood leptin, insulin and glucose concentrations, and signs of immunosuppression compared to dogs eating daily. Ten healthy adult dogs were randomized into three group and underwent three feeding regimes in a $3 \times 3$ Latin square design: twice a day feeding on a low fat (23\% energy from fat; LF) diet, $48 \mathrm{~h}$ fasting on a low fat diet, and $48 \mathrm{~h}$ fasting on a high fat enriched with medium-chain triglycerides (68\% energy from fat; HF) diet. Body weight, food intake, activity, blood glucose, $\beta$-hydroxybutyrate, leptin, ghrelin, and insulin were measured. Lymphocyte proliferation and neutrophil/macrophage phagocytosis and respiratory burst were measured as markers of immune function. Nuclear magnetic resonance spectroscopy was used to relatively quantify plasma metabolites. When the dogs were IF on a HF diet, they had the highest concentration of blood ketones (mean $0.061 \mathrm{mmol} / \mathrm{L}, \mathrm{SD}$ 0.024), whereas they had the lowest concentration (mean 0.018 $\mathrm{mmol} / \mathrm{L}, \mathrm{SD}$ 0.004) when fed daily. Blood glucose and insulin concentrations were lower in IF dogs on a HF diet compared to daily feeding or IF on a LF diet. There was an increase in plasma $\beta$-hydroxybutyrate concentrations, and a reduction in glucose and insulin concentrations when dogs were IF on a HF diet. There was only a decline in the immune parameters studied when the dogs were IF on a LF diet, which was not seen when on the HF diet. The results of this study indicate the potential of IF to be further investigated as a potential beneficial feeding regime for dogs.

Keywords: fasting, ketone, beta-hydroxybutyrate, ketogenic, diet, dog, medium-chain, immunity 


\section{INTRODUCTION}

Optimal feeding regimens for both veterinary and human hospitalized patients have not yet been established. Underfeeding is common during hospitalization and is associated with depressed immunity, increased readmission rates, and increased mortality (1-4). However, overfeeding critically ill patients has also been shown to have deleterious effects (5-7). In particular, iatrogenic hyperglycemia can lead to impaired wound healing, neuronal dysfunction, increased production of the inflammatory cytokines interleukin-6 (IL-6) and tumor necrosis factor- $\alpha$ (TNF$\alpha$ ), inhibition of leukocyte function, vasculitis, and ultimately a poorer clinical outcome (8-13). Some of these effects can be abrogated when blood glucose is normalized $(9,14)$. So whereas clinicians want to provide appropriate nutrition for hospital patients, they need to establish the best means of doing so, while avoiding hyperglycemia.

A potentially effective feeding regime to achieve these agnostic goals is intermittent fasting. Intermittent fasting is the process of reducing meal frequency in order to prolong the period of fasting between meals, but without necessarily restricting total caloric intake when expressed over a longer period of time. Extending the period of fasting between meals has been found to increase insulin sensitivity, reduce serum fructosamine, reduce cancer cell proliferation, reduce concentrations of proinflammatory cytokines IL- 6 , IL- $1 \beta$, and TNF- $\alpha$ in circulation, delay aging, and improve neuronal repair following injury when compared to continuous feeding (15-25). In healthy mice, blood glucose and insulin concentrations were reduced following a period of intermittent fasting (21). Several mechanisms have been proposed including the reduction of mitochondria-derived reactive oxygen species, activation of sirtuins and associated promotion of autophagy and cell cleansing, and decreased expression of p38 mitogen-activated protein kinase, an upstream mediator of apoptosis $(18,26-28)$. These potential mechanisms would allow a reduction in oxidative stress and a more tailored repair response following injury.

An intermittent fasting regime is of particular interest in patients with spinal disease, as it has been shown to reduce lesion size and improve recovery in rodent models of spinal injury compared with daily feeding (21-23). Ketones, which increase during the fasting period, upregulate nicotinamide adenine dinucleotide $(\mathrm{NAD})^{+}$-dependent sirtuin 3 and superoxide dismutase, increases the expression of autophagy-promoting protein forkhead box O3a, and reduces neuronal injury in the cerebral cortex of rats following experimentally induced hypoglycemia $(29,30)$. In addition, ghrelin, an orexigenic peptide secreted by the stomach in a fasted state, protects neurons from ischemia and reperfusion injury in vivo, and decreases the expression of the TNF- $\alpha$ and IL- $1 \beta$ from microglial cells in Parkinson-modeled mesencephalic neuronal cell cultures $(31,32)$. Thus, intermittent fasting may be a feeding strategy that promotes neuronal recovery while also avoiding hyperglycemia.

Although there are many potential benefits to intermittent fasting, there are possible detrimental consequences as well. Humoral and cellular immune functions are known to decrease in a fasted state, which is in part the result of a drop in the plasma adipokine, leptin $(33,34)$. Leptin increases neutrophil chemotaxis and macrophage phagocytosis, and affects the maturation of Tcells (35). Short-term fasting in several species reduces T-cell mediated responses, and splenic and peripheral immune cell numbers $(17,36,37)$. Injection of leptin into fasted or leptindeficient $\mathrm{ob} / \mathrm{ob}$ mice reverses the suppression of lymphocyte differentiation, macrophage phagocytosis, and delayed-type hypersensitivity responses caused by leptin deficiency (34, 38, 39). However, rats consuming a high fat diet attenuates the drop in leptin during fasting, and increases ketone production between meals $(40,41)$. In addition, feeding medium-chain triglycerides (MCTs) promotes the formation of ketones in the fed state $(42,43)$. After eating, the majority of mediumchain fatty acids are absorbed through the portal circulation and are metabolized by hepatocytes into ketones $(44,45)$. So feeding a high fat diet enriched with MCTs may have the dual benefit of maintaining leptin serum concentration while also promoting ketogenesis during the short periods of fasting. Therefore, intermittent fasting on a high fat diet enriched with MCTs may be preferential.

The principal aim of this study was to determine the metabolic and immunological effects of a $48 \mathrm{~h}$ intermittent fasting regime in healthy dogs. Our primary hypothesis was that dogs undergoing intermittent fasting would have higher plasma concentrations of $\beta$-hydroxybutyrate and ghrelin, and lower concentrations of glucose, insulin, and leptin compared with dogs fed daily. Our secondary hypothesis was that dogs undergoing an intermittent fasting regime on a high fat diet enriched with medium-chain triglycerides would have a greater blood $\beta$-hydroxybutyrate and leptin concentrations compared with dogs intermittently fasted on a low fat diet.

\section{MATERIALS AND METHODS}

\section{Animals}

Following a complete physical examination, 10 healthy, adult dogs from Massey University's Canine Nutrition Unit were used in this study. The dogs were of two breeds: Harrier Hounds ( $n$ $=7$ ) and New Zealand Huntaways $(n=3)$, and were composed of four neutered males and six speyed females. The dogs had a mean age of 7.1 (SD 2.1) years, mean body weight of 27.8 (SD 3.1) kilograms, and a mean body condition score (BCS) of 4.2 (SD 0.4 ). The study protocol was approved by the Massey University Animal Ethics Committee (MUAEC \#16/130).

\section{Study Design}

A week before the commencement of the study, all dogs were transitioned onto a high carbohydrate, low fat commercial dry diet to allow for acclimation. The dogs were fed to meet their maintenance energy requirement based on historical colony data. After this acclimation period, the dogs were randomized into one of three groups which underwent each feeding trial regime in a $3 \times 3$ Latin-square design with a weeklong "wash out" duration in-between. The three feeding regimes were as follows: (1) daily fed feeding on a low fat (LF), high carbohydrate diet (BID), (2) intermittent fasting (feeding once every $48 \mathrm{~h}$ ) 
on the same LF diet (IF LF), and (3) intermittent fasting (feeding once every $48 \mathrm{~h}$ ) on a high fat (HF) diet (IF HF). Both diets used in this study were formulated to meet the nutrient requirements for adult dogs defined by the Association of American Feed Control Officials (AAFCO). A commercial dry food ${ }^{1}$ was chosen as the low-fat, high carbohydrate diet. The high fat diet was created using the same dry commercial diet with the addition of powdered whey protein, beef tallow, sunflower oil, coconut oil and a multivitamin/mineral $\mathrm{mix}^{2}$ to ensure adequacy of the total diet. The total amount of medium-chain triglycerides $(\mathrm{C} 8, \mathrm{C} 10, \mathrm{C} 12)$ from the coconut oil and beef tallow amounted to $14.7 \%$ of the total calories in the diet when using an energy of $6.8 \mathrm{kcals} / \mathrm{gram}$ for the MCTs (46). The nutrient profiles of both diets are presented in Table 1.

When dogs were in the daily feeding regime, they were offered their maintenance energy requirement divided equally into two meals that were provided in the morning and the afternoon. When the dogs were in the intermittent fasting regime, they were offered twice their maintenance energy requirement in the morning every other day. The dogs were allowed up to $3 \mathrm{~h}$ to consume their meal, after which the food was removed and weighed. During the wash out period between feeding regimes, all dogs were placed on the commercial high carbohydrate, low fat dry diet and fed twice a day for 1 week.

On days 1, 3, 5, and 7 of a trial period, a fasted blood sample $(12 \mathrm{~mL}$ in total) was collected into lithium heparin and plain red-top vacutainers ${ }^{3}$ from all dogs by jugular venipuncture before food was offered. Day 1 represented an overnight-fasted, baseline sample, while the samples collected on days 3, 5, and 7 represented either a $12 \mathrm{~h}$ fast when the dogs were eating daily, or a $48 \mathrm{~h}$ fast when the dogs were fasted intermittently. Immediately following blood collection, a protease inhibitor ${ }^{4}$ was added to the sample in the plain red-top vacutainer to prevent ghrelin degradation. All samples were placed on ice until they were centrifuged, and serum and plasma removed. Daily food intake, weekly body weight and body condition score were recorded for all dogs. To compare the caloric intake of the dogs on the different feeding regimes, the total calories eaten every 2 days (i.e., days 1 and 2, days 3 and 4, days 5 and 6) was divided by the weekly starting weight of each dog to the power of 0.75 in order to express intake as kcal per $48 \mathrm{~h} / \mathrm{kgBWT}^{0.75}$. In addition, day ( 5 am to $8 \mathrm{pm}$ ) and night ( $8 \mathrm{pm}$ to $5 \mathrm{am}$ ) activity of the dogs was measured using a tri-axial accelerometer ${ }^{5}$ fitted to their collar.

After blood sampling on day 7, all dogs were placed onto the "wash out" feeding regime. Following a wash out, each group was fed according to their next assigned feeding regime, and blood samples taken as described above. This was repeated again once more so that all groups underwent each of the three different feeding regimes with a washout period in between.

\footnotetext{
${ }^{1}$ Eukanuba Large Breed Weight Control dry, Mars Incorporate, McLean, Virginia, USA.

${ }^{2}$ Balance IT ${ }^{\circledR}$ Canine, DVM Consulting Incorporated, Davis, California, USA.

${ }^{3}$ BD Vacutainer ${ }^{\circledR}$, Plymouth, United Kingdom.

${ }^{4}$ Millipore ${ }^{\circledR}$ DPP-IV Inhibitor, Darmstadt, Germany.

${ }^{5}$ Heyrex ${ }^{\circledR}$, Say Systems, Wellington, New Zealand.
}

TABLE 1 | The nutrient profile of the low fat commercial diet and the modified high fat diet.

\begin{tabular}{|c|c|c|c|}
\hline & $\begin{array}{l}\text { Commercial } \\
\text { low fat diet }\end{array}$ & $\begin{array}{c}\text { Modified } \\
\text { high fat diet }\end{array}$ & $\begin{array}{c}\text { Percentage } \\
\text { difference (\%) }\end{array}$ \\
\hline Protein energy (\%ME) & 22 & 22 & 100.00 \\
\hline Fat energy (\%ME) & 23 & 68 & 295.57 \\
\hline Carbohydrate energy (\% ME) & 55 & 10 & 18.19 \\
\hline Protein (g/Mcal) & 62.79 & 62.95 & 100.26 \\
\hline Total lipid (g/Mcal) & 26.91 & 79.41 & 295.08 \\
\hline $\begin{array}{l}\text { Linoleic acid (18:2 n-6) } \\
\text { (g/Mcal) }\end{array}$ & 8.16 & 9.37 & 114.75 \\
\hline Carbohydrate (g/Mcal) & 157.57 & 29.92 & 18.99 \\
\hline Choline (mg/Mcal) & 717.60 & 670.54 & 93.44 \\
\hline Folate (mcg DFE/Mcal) & 209.30 & 388.12 & 185.44 \\
\hline Niacin (mg/Mcal) & 14.35 & 21.99 & 153.23 \\
\hline Pantothenic acid (mg/Mcal) & 7.41 & 7.30 & 98.42 \\
\hline Riboflavin (mg/Mcal) & 2.03 & 2.34 & 115.30 \\
\hline Thiamin (mg/Mcal) & 1.11 & 0.70 & 63.56 \\
\hline Vitamin A (mcg RAE/Mcal) & 4041.86 & 1301.85 & 32.21 \\
\hline Vitamin B-12 (mg/Mcal) & 0.018 & 0.017 & 94.44 \\
\hline Vitamin B-6 (mg/Mcal) & 2.09 & 1.17 & 56.09 \\
\hline $\begin{array}{l}\text { Vitamin E ( } \alpha \text {-tocopherol) } \\
\text { (IU/Mcal) }\end{array}$ & 74.75 & 88.18 & 117.97 \\
\hline Calcium (g/Mcal) & 2.84 & 3.13 & 110.39 \\
\hline Copper (mg/Mcal) & 4.34 & 3.15 & 72.64 \\
\hline lodine (mg/Mcal) & 0.94 & 0.71 & 75.77 \\
\hline Iron (mg/Mcal) & 45.71 & 34.39 & 75.24 \\
\hline Magnesium (g/Mcal) & 0.32 & 0.27 & 85.31 \\
\hline Manganese (mg/Mcal) & 15.03 & 4.55 & 30.29 \\
\hline Phosphorus (g/Mcal) & 2.39 & 1.79 & 74.92 \\
\hline Potassium (g/Mcal) & 2.21 & 2.59 & 116.90 \\
\hline Selenium (mg/Mcal) & 0.14 & 0.10 & 69.23 \\
\hline Sodium (g/Mcal) & 1.20 & 0.50 & 41.39 \\
\hline Zinc (mg/Mcal) & 63.39 & 52.99 & 83.59 \\
\hline Vitamin D (IU/Mcal) & 447.00 & 275.92 & 61.73 \\
\hline
\end{tabular}

The high fat diet was created using the commercial low fat diet with the addition of whey protein isolate, beef tallow, sunflower oil, coconut oil, and a multivitamin/mineral mix. Both diets were formulated to meet the nutrient requirements for adult dogs as defined by the Association of American Feed Control Officials (AAFCO).

\section{$\beta$-Hydroxybutyrate, Glucose, and Metabolomics}

Within $1 \mathrm{~h}$ of collection, plasma was harvested from the heparin vacutainers following centrifugation for $10 \mathrm{~min}$ at 3,000 $\mathrm{rcf}$ at $4^{\circ} \mathrm{C}$. Plasma glucose was analyzed using a handheld glucometer 6 which has been previously validated for use in dogs (47). The remaining plasma was stored at $-80^{\circ} \mathrm{C}$ until further analysis.

$\beta$-hydroxybutyrate was assayed in plasma samples from days 3,5 , and 7 of each regime using a colorimetric assay ${ }^{7}$ according to the manufacturer's instructions. The thawed plasma samples were initially de-proteinated using $10 \mathrm{kD}$ spin columns ${ }^{8}$ and centrifuged at 10,000 $\mathrm{rcf}$ for $10 \mathrm{~min}$. The samples were then

\footnotetext{
${ }^{6}$ Accu-check ${ }^{\circledR}$ Performa, Roche Diagnostics Limited, Mannheim, Germany.

${ }^{7}$ beta HB Assay Kit, catalogue \#ab83390, Abcam, Cambridge, United Kingdom.

${ }^{8} 10 \mathrm{kD}$ spin column, catalogue \#ab93349, Abcam, Cambridge, United Kingdom.
} 
prepared and absorbance at $450 \mathrm{~nm}$ was measured using a microplate reader ${ }^{9}$.

Nuclear magnetic resonance (NMR) was used for plasma metabolomics. Samples were prepared based on the protocol described in a previous study (48). Briefly, $300 \mu \mathrm{L}$ of plasma was deproteinated using $600 \mu \mathrm{L}$ of methanol and incubated at $-20^{\circ} \mathrm{C}$ for $30 \mathrm{~min}$. The samples were then centrifuged at $13,400 \mathrm{rcf}$ for $30 \mathrm{~min}$ and the supernatant was removed and placed in a rotary evaporator for $3.5 \mathrm{~h}$ at $20^{\circ} \mathrm{C}$. Any remaining supernatant in the samples was then dried completely by freeze drying. The dried samples were then stored in screw top vials ${ }^{10}$ at $-80^{\circ} \mathrm{C}$ until analysis. On the day of analysis, a phosphate buffer solution was prepared by dissolving $928.6 \mathrm{mg}$ of anhydrous $\mathrm{NaH}_{2} \mathrm{P}_{4}$ and $320.9 \mathrm{mg}$ of anhydrous $\mathrm{Na}_{2} \mathrm{HPO}_{4}$ in $100 \mathrm{~g}$ of $\mathrm{D}_{2} \mathrm{O}$, and used with further $\mathrm{pH}$ modification. The dried samples were reconstituted using $600 \mu \mathrm{L}$ of phosphate buffered $\mathrm{D}_{2} \mathrm{O}$, along with two standards [0.5 mM of 2,2-dimethyl-2-silapentane-5-sulfonate sodium salt $(\mathrm{DSS})^{11}$ and $5 \mathrm{mM}$ imidazole ${ }^{12}$ ] to allow for adjustments in chemical shifts and $\mathrm{pH}$. The samples were then transferred to $5 \mathrm{~mm} \mathrm{NMR}$ tubes ${ }^{13}$ and analyzed using a cyroprobeequipped Bruker Avance $700 \mathrm{MHz}$ spectrometer (Bruker Biospin, Rheinstetten, Germany) operating at $700.13 \mathrm{MHz}$. The samples were measured at $25^{\circ} \mathrm{C}$ using a standard $1 \mathrm{D}$ NOESY pulse sequence with presaturation of the residual water signal. Spectra were recorded using 58k points and an acquisition time of $3.5 \mathrm{~s}$ followed by a relaxation delay of $1.5 \mathrm{~s}$. TopSpin v3.0 (Bruker Biospin) was used to process the ${ }^{1} \mathrm{H}$ NMR spectra. Phasing and baseline correction of all NMR spectra were checked manually.

\section{Endocrinology}

The plain red-top vacutainers were centrifuged for $10 \mathrm{~min}$ at 3,000 rcf at $4^{\circ} \mathrm{C}$, and serum removed within $1 \mathrm{~h}$ of collection. The serum was stored at $-80^{\circ} \mathrm{C}$ until analysis. Leptin, ghrelin, and insulin were assayed using a commercial multiplex immunoassay ${ }^{14}$. Samples were prepared following the manufacturer's instruction. Briefly, $50 \mu \mathrm{L}$ of serum was added to a 96-well plate to which a buffer and antibody-conjugated beads were added. The plates were gently agitated overnight at $4^{\circ} \mathrm{C}$. Following this, the plates were washed, detection antibodies added and finally analyzed using a multiplex reader ${ }^{15}$.

\section{Immunological Assays}

Whole blood from the lithium vacutainers was utilized within an hour of collection. Leucocyte phagocytosis and respiratory burst were assayed by flow cytometry using a cell analyzer ${ }^{16}$

\footnotetext{
${ }^{9}$ VersaMax ${ }^{\text {TM }}$ Microplate Reader, Molecular Devices LLC, San Jose, California, USA.

${ }^{10}$ Cryo. $S^{\mathrm{TM}}$, Greiner Bio-One, Frickenhausen, Germany.

${ }^{11}$ DSS, Sigma-Aldrich, St. Louis, MI, USA.

${ }^{12}$ Imidazole, Sigma-Aldrich, St. Louis, MI, USA.

${ }^{13} 5 \mathrm{~mm}$ NMR Sample Tubes, Wilmad-LabGlass, Vineland, New Jersey, USA.

${ }^{14}$ Milliplex ${ }^{\circledR}$ MAP Canine Gut Hormone Magnetic Bead Panel, Millipore, Burlington, Massachusetts, USA.

${ }^{15}$ Luminex $200^{\mathrm{TM}}$, Merck, Darmstadt, Germany.

${ }^{16}$ BD FASCSCalibur $^{\mathrm{TM}}$, BD Sciences, San Jose, California, USA.
}

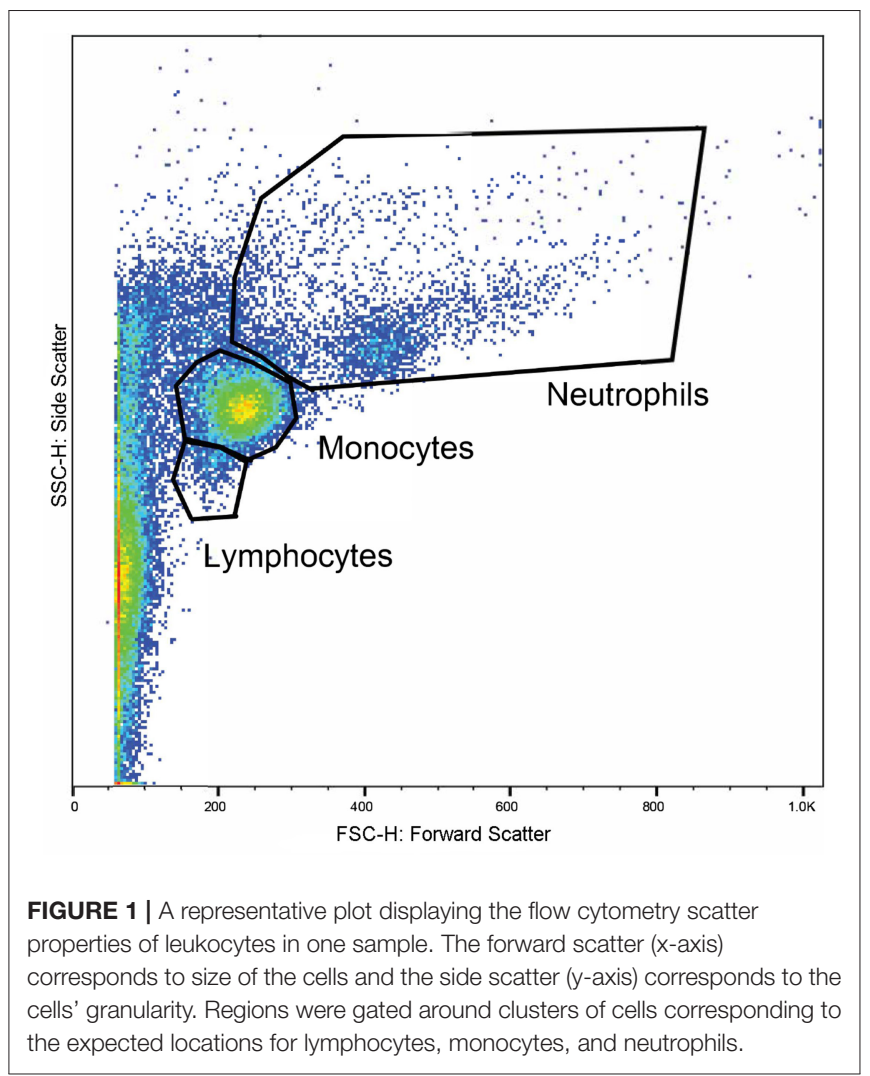

and fluorescent markers for phagocytosis ${ }^{17}$ and oxidative burst ${ }^{18}$. A modified protocol was used which was based on previously published works $(49,50)$. Four flow cytometry tubes were prepared for each sample. In each tube, $100 \mathrm{uL}$ of whole blood was incubated at $37^{\circ} \mathrm{C}$ for $30 \mathrm{~min}$ with either 10 $\mu \mathrm{L}$ of $143 \mu \mathrm{M}$ DHR solution, $50 \mu \mathrm{L}$ of $\mathrm{pHrodo}^{\mathrm{TM}}$, both compounds, or nothing added. After incubation, $2.7 \mathrm{~mL}$ of deionized water was added to lyse erythrocytes. Within 2 min of adding the deionized water, $300 \mu \mathrm{L}$ of $10 \mathrm{X}$ PBS was added and samples centrifuged at $600 \mathrm{rcf}$ for $7 \mathrm{~min}$. The supernatant was decanted, and the process repeated with $3 \mathrm{~mL}$ of PBS. Then, 3\% formaldehyde in PBS was added and samples incubated at room temperature for $5 \mathrm{~min}$ for fixation. Finally, $2 \mathrm{~mL}$ of PBS was added, and samples were centrifuged at $350 \mathrm{rcf}$ for $7 \mathrm{~min}$. The supernatant was removed, and the pellet suspended in $200 \mu \mathrm{L}$ PBS with $2 \%$ fetal calf serum (FCS) in $5 \mathrm{~mL}$ polystyrene round bottomed tubes ${ }^{19}$. Samples were acquired with a flow cytometer ${ }^{20}$ until at least 10,000 events were collected. Lymphocyte, monocyte, and neutrophil populations were identified based on size and granularity in a forward and side scatter plot (Figure 1). Quadrants for single and double positive cells were demarcated using the

\footnotetext{
${ }^{17}$ pHodo $^{\text {TM }}$ Red S. aureus Bioparticles ${ }^{\mathrm{TM}}$, catalog number A10010, Invitrogen ${ }^{\circledR}$, Carlsbad, California, USA.

${ }^{18}$ Dihydrorhodamine 123, catalog number D23806, Invitrogen $\AA$, Carlsbad, California, USA.

${ }^{19}$ BD Falcon ${ }^{\mathrm{TM}}$ tubes, BD Biosciences, San Jose, California, USA

${ }^{20}$ FACSCalibur ${ }^{\mathrm{TM}}$, BD Biosciences, San Jose, California.
} 
set of control samples (Figure 2). The results of the gated populations were expressed as the percentage positive for cells undergoing phagocytosis and/or respiratory burst, and their mean fluorescence intensity.

Lymphocyte proliferation was performed on heparinized whole blood. For each sample, $25 \mu \mathrm{L}$ of blood was transferred into eight wells on a $96 \mathrm{U}$-well plate. Then, $200 \mathrm{ng} / \mathrm{mL}$ of Staphylococcus enterotoxin B (SEB)/lipopolysaccharides (LPS) solution was added to four of the wells. The plates were then incubated at $37^{\circ} \mathrm{C}$ in $5 \% \mathrm{CO}_{2}$ humidified atmosphere for 3 days. Following this, $50 \mu \mathrm{L}$ of ${ }^{3} \mathrm{H}$-thymidine of a $10 \mu \mathrm{Ci} / \mathrm{mL}$ stock solution was added to each well. The plate was incubated for $4 \mathrm{~h}$ at $37^{\circ} \mathrm{C}$ in $5 \% \mathrm{CO}_{2}$ humidified atmosphere for $4 \mathrm{~h}$ and then stored at $-80^{\circ} \mathrm{C}$ until analysis. The cells were then harvested and counted using liquid scintillation.

\section{Sample Size}

An a priori power analysis was performed using a desired mean difference and previously published standard deviations for key metabolites and hormones. The mean difference and standard deviation (SD) used in the power analysis were: $\beta$ hydroxybutyrate 0.05 (SD $0.01 \mathrm{mmol} / \mathrm{L})$, ghrelin 75 (SD 53 $\mathrm{pg} / \mathrm{mL}$ ), leptin 3,000 (SD 3,000 pg/mL), and insulin 220 (SD $150 \mathrm{pg} / \mathrm{mL}$ ). This indicated that a sample size of 10 dogs would be necessary for significance level $(\alpha)$ of 0.5 and a power of $80 \%$ to detect a difference in $\beta$-hydroxybutyrate, ghrelin, leptin, and insulin.

\section{Statistical Analysis Metabolomics}

For analysis, the NMR spectra were divided into $0.04 \mathrm{ppm}$ spectral buckets, where the regions corresponding to water and DSS (4.68 to $4.88,-0.1$ to $0.1 \mathrm{ppm}$, respectively) were excluded, along with the following additional regions 5.51 to 5.84 , 5.92 to 6.07 , and 6.11 to 6.31 . All spectra were normalized by total intensity.

The relationship between the diet groups and the metabolome was explored using principal component analysis (PCA), partial
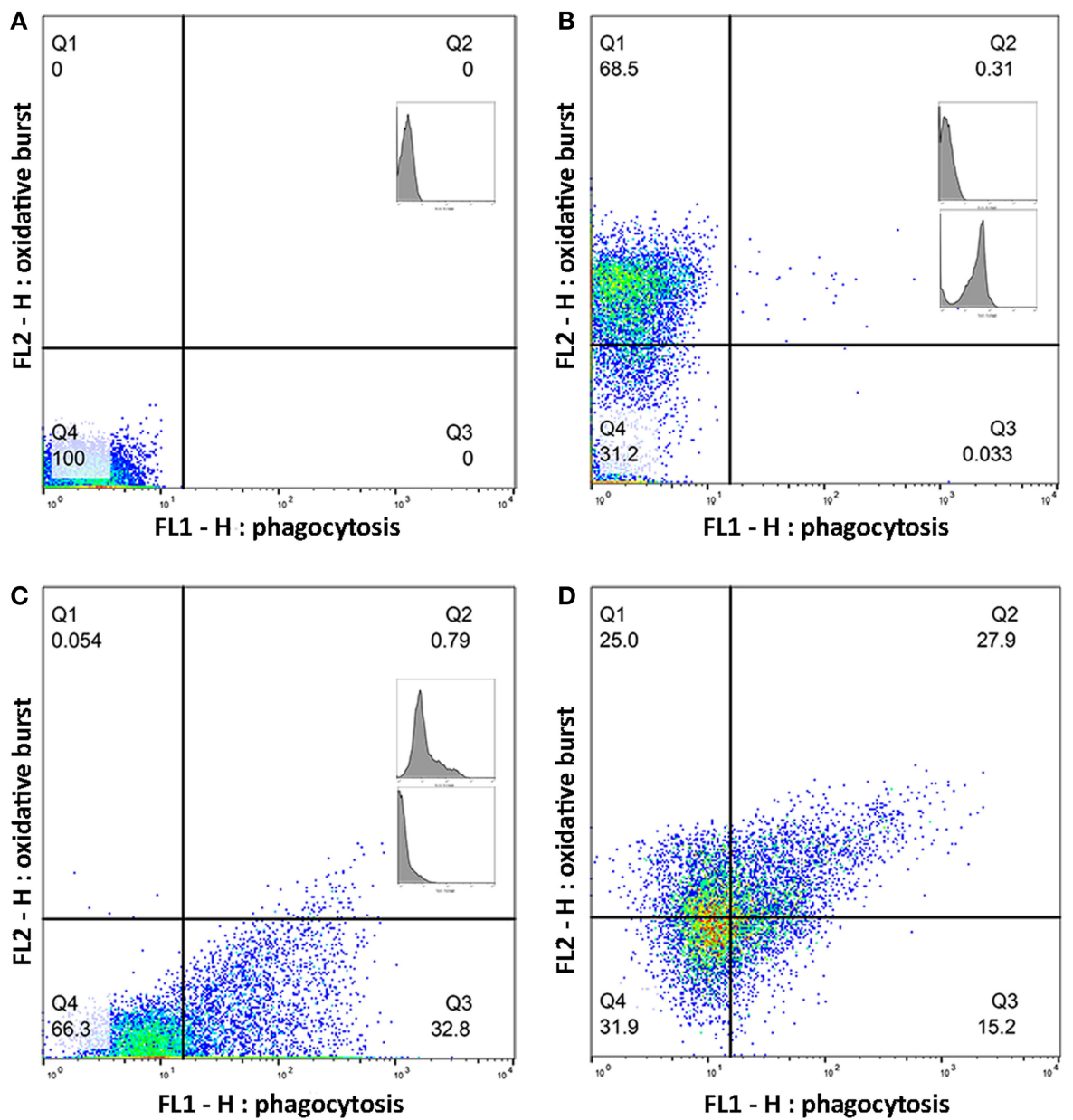

FIGURE 2 | Quadrants for single and double positive cells were established using a set of control samples. Plots (A-D) show a representative sample of gated monocytes from one sample. The number in each quadrant is the percentage of cells. (A) Monocytes without a flurochrome added. (B) Monocytes with only

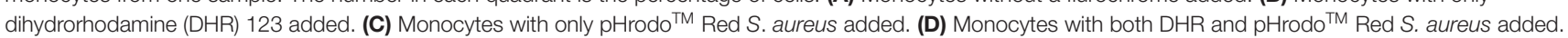


least squares-discriminant analysis (PLS-DA) and orthogonal partial least squares discriminant (OPLS-DA) analysis were performed using SIMCA v13.0 (Umetrics, Sweden). These statistical methods can reveal clustering of samples into different groupings based on differences of metabolite concentrations across the sample population. PCA is an unsupervised method and is perhaps the most robust. PLS-DA and OPLS-DA are so-called supervised methods and use a priori knowledge of the group membership to fit the data and maximize separation of data from these groups. Pareto scaling was used for the supervised models and the PLS models were validated by permutation testing to rule out overfitting. The spectral buckets that contributed to the greatest variance in the samples were identified from loading plots and subsequently assigned to their associated metabolites using the Chenomx metabolite library v8.3 (Chenomx Inc., Alberta, Canada). The metabolite concentrations were then quantified using manual fitting of the spectral peaks in the Chenomx NMR Suite. Concentrations of plasma $\beta$-hydroxybutyrate measured by the colorimetric assay were compared to the concentrations obtained from the fitted spectra using "BlandAltmanLeh" v0.3.1 package (51) in the R Studio v1.1.456 statistical software (52).

\section{Modeling}

The "lme4" package (53) in the R Studio v1.1.456 statistical software (54) was used to perform a linear mixed effects analysis of the relationship between the outcome variables [change in weight, intake, activity, glucose, $\beta$-hydroxybutyrate, leptin, ghrelin, insulin, homeostatic model assessment (HOMA), NMR metabolites, lymphocyte proliferation and flow cytometry results], and the fixed variables (time, diet, age, sex, and BCS). Separate models were fitted for each outcome variable. Dog was included as a random effect to account for repeated measures.
Interactions between the fixed variables, and between diet and diet sequence, were not significant, and so were not included in the final models.

If the visual inspection of the residual quantile-quantile plots and the Shapiro-Wilk test of the residuals indicated a deviation from normality or homoscedasticity, then transformations of the dependent variable were performed in attempts to improve consistency on the assumptions of the model. However, transformation did not lead to a change in the interpretation of the models or our conclusions. Therefore, for simplicity, the graphs, and final model are reported with the untransformed data.

A post-hoc pairwise comparison of the estimated marginal means with Tukey's correction was performed when diet was significant in the final model. The results of the mixed effects models are presented as the means and standard error of means. $P \leq 0.001$ were considered indicative of very strong evidence, $p$ $\leq 0.01$ of strong evidence, $p \leq 0.05$ of moderate evidence, $p \leq 0.1$ of weak evidence, and $p \leq 0.1$ of insufficient evidence (55).

\section{RESULTS}

\section{Intake, Body Weight, Body Condition Score, and Activity}

There were no differences in any of the baseline parameters before the groups began their assigned feeding regime in any of the treatment weeks $(P>0.5)$. All dogs remained at a BCS of 4 or 5 out of 9 throughout the study. When fed daily, the dogs had a higher food intake compared to when they were fed intermittently $(P<0.001)$, however, there was no difference in intake between dogs when intermittently fed on the LF or the HF diets $(P=0.395$, Table 2$)$. Male dogs consumed more

TABLE 2 | The means and standard deviations of food intake, change in bodyweight, and activity in 10 dogs fed daily (BID), and intermittently fasted on a low fat (IF LF) and a high fat diet (LF HF) in a Latin Square design.

\begin{tabular}{|c|c|c|c|c|c|c|c|}
\hline Outcome & Diet & Mean & Standard deviation & Fixed effect & Estimate & Standard error & $P$-value \\
\hline Intake & BID & 295 & 40 & (Intercept) & 270 & 77 & \\
\hline \multirow[t]{3}{*}{$\left(\right.$ kcals$/ B W T^{0.75}$ ) } & IF LF & 230 & 49 & Diet IF LF & -66 & 13 & $<0.0001$ \\
\hline & IF HF & 214 & 73 & Diet IF HF & -81 & 12 & $<0.0001$ \\
\hline & & & & Sex male & 51 & 17 & 0.027 \\
\hline Body weight & BID & -1.7 & 1.6 & (Intercept) & -1.72 & 0.65 & \\
\hline \multirow[t]{2}{*}{ (\% change) } & IF LF & -3.3 & 2.6 & Diet IF LF & -1.56 & 0.85 & 0.067 \\
\hline & IF HF & -1.6 & 1.8 & & & & \\
\hline \multirow[t]{3}{*}{ Total activity ( $\Delta \mathrm{G})$} & $\mathrm{BID}$ & 254,058 & 78,988 & (Intercept) & 199,712 & 25,811 & \\
\hline & IF LF & 227,637 & 77,512 & Week & 13,451 & 4,126 & 0.005 \\
\hline & IF HF & 242,923 & 79,130 & & & & \\
\hline \multirow[t]{3}{*}{ Day activity ( $\Delta \mathrm{G})$} & BID & 212,251 & 69,033 & (Intercept) & 175,004 & 23,164 & \\
\hline & IF LF & 200,763 & 72,634 & Week & 11,652 & 3,378 & 0.004 \\
\hline & IF HF & 219,528 & 72,006 & & & & \\
\hline \multirow[t]{3}{*}{ Night activity $(\Delta G)$} & BID & 39,458 & 15,615 & (Intercept) & 39,458 & 3,829 & \\
\hline & IF LF & 28,261 & 8,872 & Diet IF LF & $-11,197$ & 4,599 & 0.028 \\
\hline & IF HF & 26,319 & 8,017 & Diet IF HF & $-13,665$ & 4,771 & 0.012 \\
\hline
\end{tabular}

Also included are the results of the linear mixed effect models. Only independent variables with a $P \leq 0.1$ are shown. 


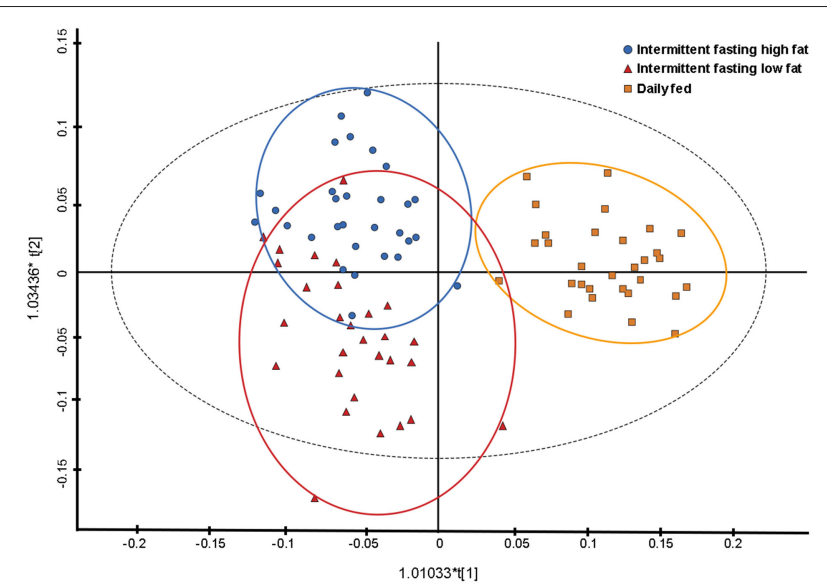

FIGURE 3 | Orthogonal partial least square with discriminant analysis (OPLS-DA) plot illustrating the effect of three feeding regime on the plasma metabolome of 10 dogs. Each point represents a single sample with the blue circles representing a dog intermittently fasted on a high fat diet, the red triangles representing a dog intermittently fasted on a low fat diet, and the orange squares representing a dog fed daily on a low fat diet.

food per $\mathrm{kgBWT}^{0.75}$ than female dogs (mean $277 \pm 67$ vs. $226 \pm 50 \mathrm{kcals} / \mathrm{kgBWT}^{0.75}$ ). The dogs lost more weight when intermittently fasted on a low fat diet, but there was no difference in the percentage of body weight change when the dogs were daily fed compared to when they were intermittently fasted on a high fat diet regime (Table 2). In addition, when the dogs were fed daily, they were more active at night compared to when they were intermittently fed the LF $\operatorname{diet}(P=0.028)$ and HF $\operatorname{diet}(P=0.012)$.

\section{Metabolites}

\section{Metabolomics}

Principal component analysis indicated some separation between the diet groups, with the first two principal components accounting for 45.6 and $9.1 \%$ of the variance, respectively. Further analyses with a supervised orthogonal partial least squares discriminant model showed a complete separation of the daily fed group and the intermittently fasted groups, and clustering of the two intermittently fasted groups (Figure 3). The metabolites associated with the spectral buckets that separated the different feeding regimes the greatest were $\beta$ hydroxybutyrate, lactate, alanine and glucose.

\section{$\beta$-Hydroxybutyrate Assayed via Kit and NMR}

The concentrations of plasma $\beta$-hydroxybutyrate on day 3,5 , and 7 were highest when the dogs were intermittently fasted on the HF diet, and lowest when the dogs were fed daily (Figure 4). There was no effect of day. Intermittent fasting increased plasma $\beta$-hydroxybutyrate concentrations regardless of the diet fed, and a higher body condition score was associated with a decrease in plasma $\beta$-hydroxybutyrate (Table 3). There was no association between weight loss and plasma $\beta$-hydroxybutyrate concentrations $(P=0.198)$. There was reasonable agreement between the $\beta$-hydroxybutyrate concentrations obtained from the colorimetric kit and from NMR (Figure 5, Bland Altman).

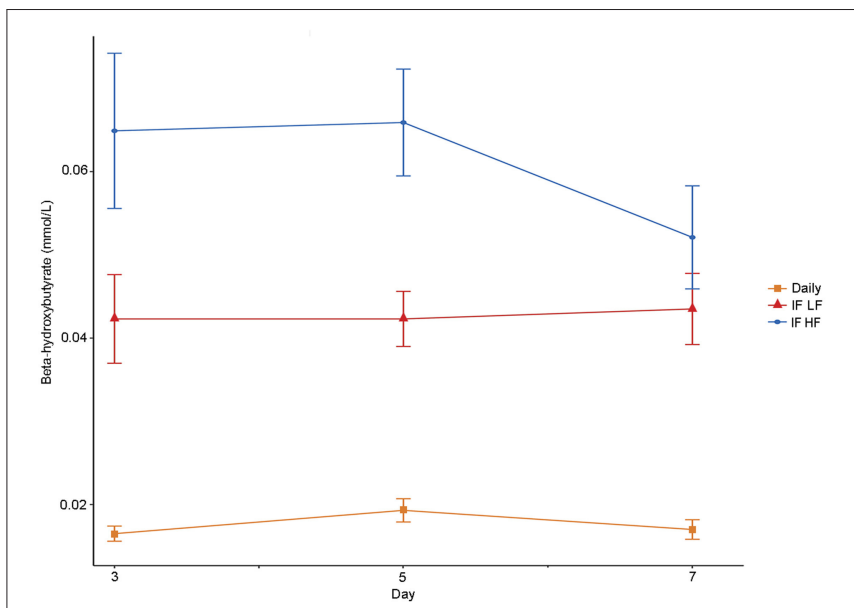

FIGURE 4 | Mean concentrations ( \pm SE) of fasted plasma beta-hydroxybutyrate in 10 dogs fed daily (square), and intermittently fasted on a low fat (triangle) and a high fat diet (circle) in a Latin Square design.

\section{Lactate and Alanine via NMR}

Both lactate and alanine concentrations were lowest when the dogs were intermittently fasted on a high fat diet (Figure 6). In addition, lactate concentrations decreased over time $(P=0.009$; Table 3).

\section{Glucose}

Blood glucose concentrations increased over time from day 3 to day 7 , and were highest in the dogs fed daily (Figure 7). There was no difference in glucose concentrations when the dogs were intermittently fasted on the LF and HF diets $(P=0.98)$. There was also no effect of BCS on blood glucose $(P=0.24$; Table 3$)$.

\section{Hormones Insulin, Leptin and Ghrelin, and HOMA}

Both insulin concentrations and HOMA scores were lowest when dogs were intermittently fasted on a high fat diet (Figure 8). A higher body condition was associated with lower insulin concentrations and HOMA scores (Table 4).

Serum leptin concentration was highest when dogs were fed daily (Figure 9). In addition, there was a decrease in leptin concentrations over time (Table 4). For ghrelin, dogs fasted intermittently on a HF diet had lower serum concentrations (Figure 9).

\section{Immunoassays}

\section{Lymphocyte Proliferation}

Lymphocyte proliferation was not significantly different during any of the feeding regimes.

\section{Phagocytosis and Respiratory Burst}

When the dogs were intermittently fasted on a LF diet, they had a lower percentage of neutrophils, and a lower MFI in macrophages which underwent both phagocytosis and oxidation (Figure 10; Table 5). In addition, when on the IF LF feeding regime, the dogs also had a lower percentage of lymphocyte which underwent respiratory oxidative burst (Figure 10; Table 5). 
TABLE 3 | The means and standard deviations for $\beta$-hydroxybutyrate, lactate alanine and glucose, and the results of the linear mixed effect models, of 10 dogs fed daily (BID), and intermittently fasted on a low fat (IF LF) and a high fat diet (LF HF) in a Latin Square design.

\begin{tabular}{|c|c|c|c|c|c|c|c|}
\hline Outcome & Diet & Mean & Standard deviation & Fixed effect & Estimate & Standard error & $P$-value \\
\hline$\beta$-hydroxybutyrate & $\mathrm{BID}$ & 0.018 & 0.004 & (Intercept) & 0.115 & 0.026 & \\
\hline \multirow[t]{3}{*}{ (mmol/L) } & IF LF & 0.043 & 0.013 & Diet IF LF & 0.028 & 0.003 & $<0.0001$ \\
\hline & IF HF & 0.061 & 0.024 & Diet IF HF & 0.043 & 0.003 & $<0.0001$ \\
\hline & & & & BCS & -0.020 & 0.004 & $<0.0001$ \\
\hline Lactate & $\mathrm{BID}$ & 0.652 & 0.150 & (Intercept) & 0.597 & 0.244 & \\
\hline \multirow[t]{2}{*}{ (mmol/L) } & IF LF & 0.619 & 0.161 & Day & -0.018 & 0.005 & $<0.001$ \\
\hline & IF HF & 0.571 & 0.163 & Diet IF HF & -0.078 & 0.029 & 0.009 \\
\hline Alanine & BID & 0.222 & 0.047 & (Intercept) & 0.246 & 0.057 & \\
\hline \multirow[t]{2}{*}{ (mmol/L) } & IF LF & 0.221 & 0.036 & Diet IF HF & -0.003 & 0.009 & $<0.001$ \\
\hline & IF HF & 0.191 & 0.042 & & & & \\
\hline Glucose & $\mathrm{BID}$ & 5.7 & 0.4 & (Intercept) & 5.9 & 0.5 & \\
\hline \multirow[t]{3}{*}{ (mmol/L) } & IF LF & 5.6 & 0.3 & Day & 0.01 & 0.01 & 0.06 \\
\hline & IF HF & 5.6 & 0.3 & Diet IF LF & -0.12 & 0.06 & 0.03 \\
\hline & & & & Diet IF HF & -0.13 & 0.06 & 0.02 \\
\hline
\end{tabular}

Only independent variables with a $P \leq 0.1$ are shown.

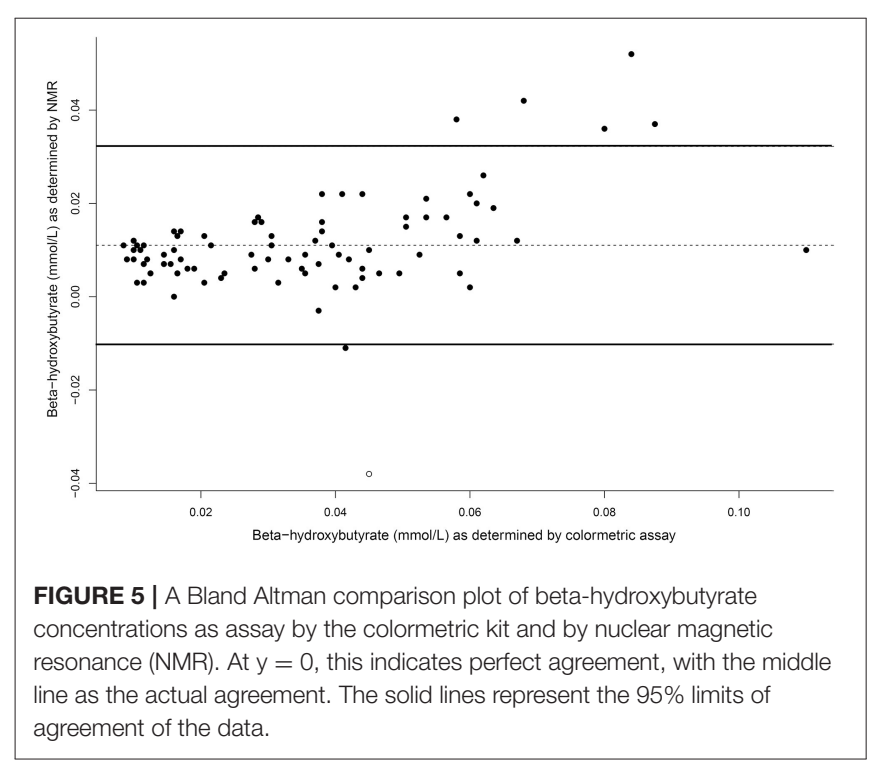

\section{DISCUSSION}

Intermittent fasting and the promotion of ketone formation may be a beneficial feeding regime for hospitalized dogs, especially spinal patients. Our primary hypothesis was that healthy, intermittently fasted dogs would have lower fasting blood glucose, insulin and leptin concentrations, and greater fasting $\beta$-hydroxybutyrate and ghrelin concentrations compared to when they were eating daily. Our secondary hypothesis was that intermittently fasted dogs eating a high fat diet enriched with medium-chain triglycerides will have higher blood $\beta$-hydroxybutyrate and leptin concentrations compared with intermittently fasted dogs eating a LF diet. We found that dogs fasted for $48 \mathrm{~h}$ on a HF diet enriched in mediumchain triglycerides promoted higher blood $\beta$-hydroxybutyrate

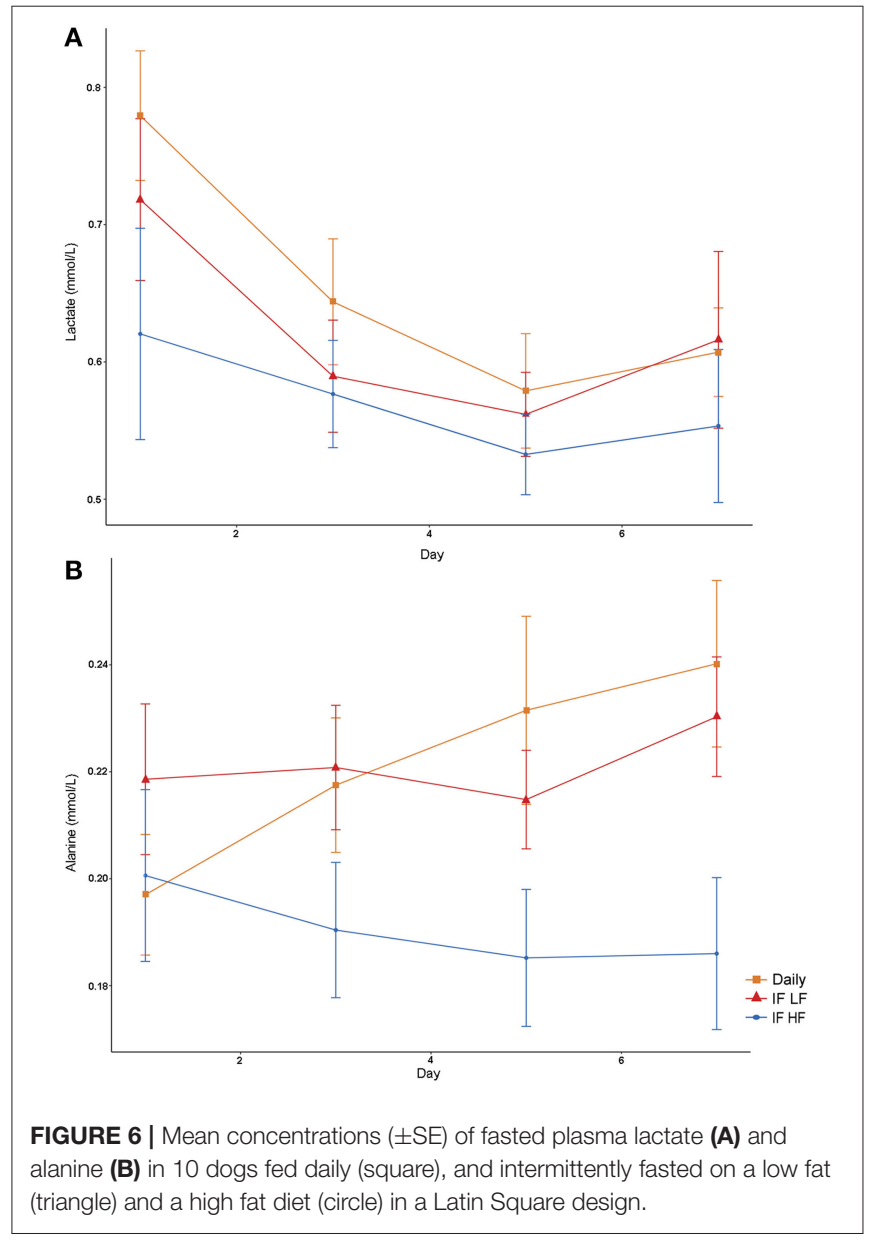

concentrations, and lower insulin concentrations than when they were fed daily or fasted on a LF diet. Leptin was not maintained during intermittent fasting by using a HF diet; however, there was 

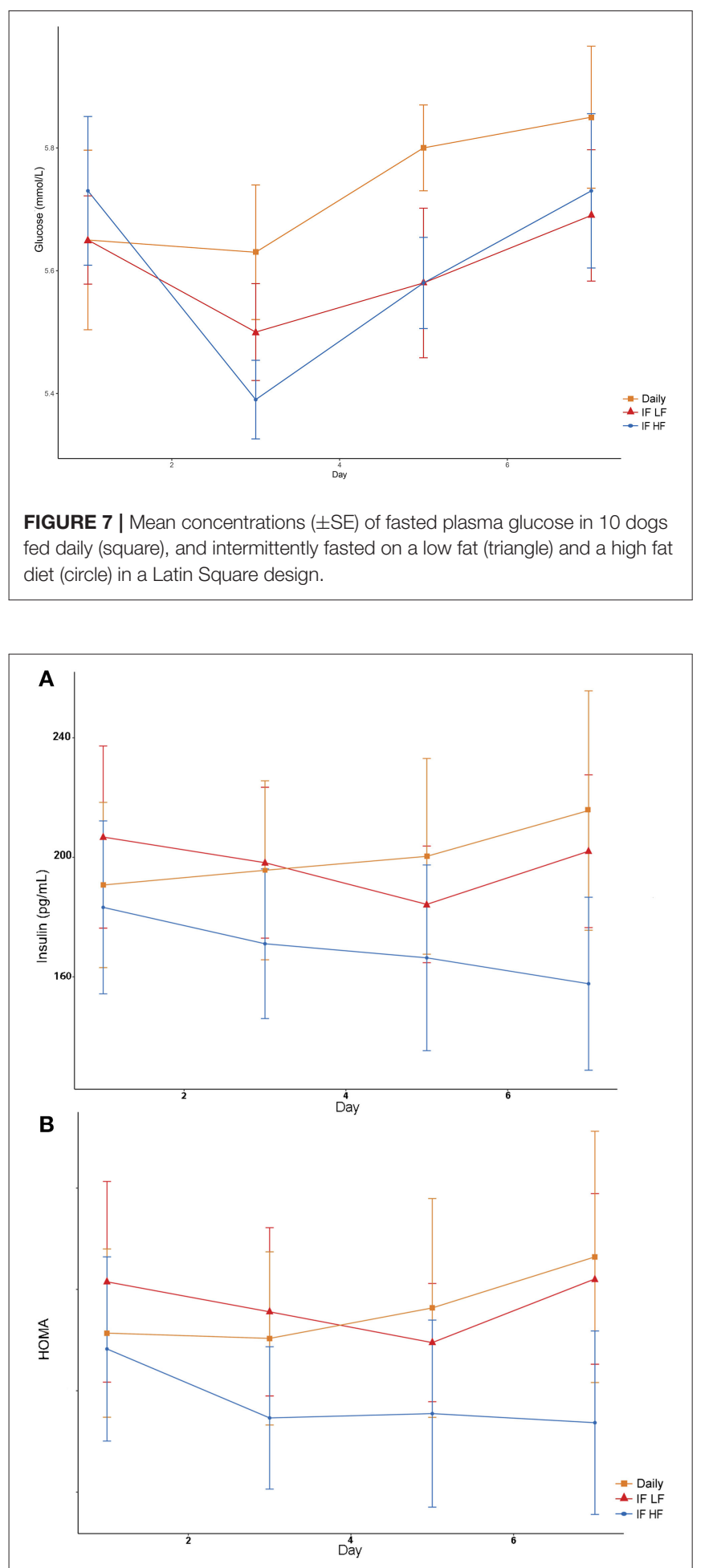

FIGURE 8 | Mean concentrations ( \pm SE) of fasted serum insulin (A) and HOMA score (B) in 10 dogs fed daily (square), and intermittently fasted on a low fat (triangle) and a high fat diet (circle) in a Latin Square design.

no difference in the immune parameters studied between when the dogs were fed the HF diet and when they were daily fed. Fasted ghrelin concentrations were lowest when the dogs were intermittently fasted on a HF diet. Overall, these findings indicate that an intermittent fasting regime on a high fat diet enriched in medium-chain triglycerides increases plasma $\beta$-hydroxybutyrate concentrations without causing immune suppression, however it did not abrogate the drop in leptin or increase ghrelin concentrations during fasting.

A commercially available LF kibble was chosen in this study as the control diet. When dogs were eating the LF diet intermittently, they consumed fewer calories and lost more weight compared to when they were eating the HF diet. There are numerous studies in several species which also show this phenomenon (56). In one study, dogs fed ad libitum a high fat diet (51\% energy from fat) gained more weight than dogs fed ad libitum on a low fat diet (23\% energy from fat) (57). Therefore, to prevent weight loss in an intermittent fasting regime, it is likely that a high fat, energy dense food is required to ensure that a dog will consume its full requirements. However, there are epidemiological associations between high dietary fat consumption and pancreatitis in dogs (58). In early experimental models, dogs fed a high fat vs. a high protein/high carbohydrate diet led to more severe clinical signs and pathological changes in the pancreas $(59,60)$. However, the diets were unlikely to have been complete and balanced rations, and so other nutrient deficiencies may have confounded the results. Giving table scraps and consuming food discarded in the trash have also been identified as risk factors for the development of pancreatitis in dogs (61). However, it is difficult to speculate what the fat contents of those items were. In contrast, feeding diets with varying fat contents, including medium-chain triglycerides, to a group of healthy dogs did not have an effect on serum canine trypsin-like immunoreactivity (cTLI), pancreatic-lipase immunoactivity (cPLI), or gastrin concentrations (62). However, the highest fat diet in this study contained only $\sim 40 \%$ fat on an energy basis. Still, there are numerous studies and reports of sled dog diets where the dogs were fed a diet with a similar fat content to our HF diet without causing pancreatitis (63-68).

Ketones provide an alternative source of energy for neurons and have been shown to reduce neuronal degeneration and improve recovery in rodent models of brain and spinal injury (30, 69-71). While $\beta$-hydroxybutyrate concentrations were highest in the dogs when they were intermittently fasted on the HF diet, the concentrations obtained (mean 0.061 , SD $0.024 \mathrm{mmol} / \mathrm{L}$ ) were much lower compared to rodents $(0.8-2 \mathrm{mmol} / \mathrm{L})$ and humans $(1.67 \mathrm{mmol} / \mathrm{L})$ fasted for a similar amount of time $(22,72,73)$. Our finding is consistent with other published studies where the dog does not reach the same blood concentration of ketones as other species after comparable fasts (74-76). However, it has been shown that the rate of total ketone production is similar between dogs and men following a $48 \mathrm{~h}$ fast $(77,78)$. Further, De Bruijne and Van den Brom (74) established that dogs have a higher rate of clearance of plasma ketones than man. Thus, the seemingly low concentration of $\beta$-hydroxybutyrate in dogs is not from reduced production of ketones, but rather from higher rates of peripheral utilization compared with rodents and humans. In addition, although a single blood sample is indicative of the concentration of a metabolite at that moment, it does not describe its flux (production and utilization) (78). The concentration of 
TABLE 4 | The means and standard deviations for insulin, Homeostatic Model Assessment (HOMA), leptin and ghrelin, and the results of the linear mixed effect models, of 10 dogs fed daily (BID), and intermittently fasted on a low fat (IF LF) and a high fat diet (LF HF) in a Latin Square design.

\begin{tabular}{|c|c|c|c|c|c|c|c|}
\hline Outcome & Diet & Mean & Standard deviation & Fixed effect & Estimate & Standard error & $P$-value \\
\hline Insulin & $\mathrm{BID}$ & 198 & 78 & (Intercept) & 449 & 123 & \\
\hline \multirow[t]{2}{*}{$(\mathrm{pg} / \mathrm{mL})$} & IF LF & 200 & 101 & Diet IF HF & -31.5 & 13.2 & 0.02 \\
\hline & IF HF & 169 & 87 & BCS & -44.1 & 19.6 & 0.03 \\
\hline Homeostatic & BID & 1.46 & 0.63 & (Intercept) & 3.22 & 0.99 & \\
\hline Model Assessment & IF LF & 1.45 & 0.76 & Diet IF HF & -0.26 & 0.011 & 0.01 \\
\hline (HOMA) & IF HF & 1.23 & 0.66 & BCS & -0.32 & 0.15 & 0.04 \\
\hline Leptin & $\mathrm{BID}$ & 2,451 & 2,217 & (Intercept) & 3,247 & 2,887 & \\
\hline \multirow[t]{3}{*}{$(\mathrm{pg} / \mathrm{mL})$} & IF LF & 1,794 & 1,683 & Day & -111 & 32 & $<0.001$ \\
\hline & IF HF & 1,729 & 1,433 & Diet IF LF & -637 & 179 & $<0.001$ \\
\hline & & & & Diet IF HF & -743 & 179 & $<0.0001$ \\
\hline Ghrelin & $\mathrm{BID}$ & 85 & 78 & (Intercept) & 8.3 & 115 & \\
\hline \multirow[t]{2}{*}{ (pg/mL) } & IF LF & 88 & 73 & Day & 6.6 & 1.4 & $<0.0001$ \\
\hline & $\mathrm{IF} \mathrm{HF}$ & 67 & 60 & Diet IF HF & -17.6 & 7.9 & 0.03 \\
\hline
\end{tabular}

Only independent variables with a $P \leq 0.1$ are shown.

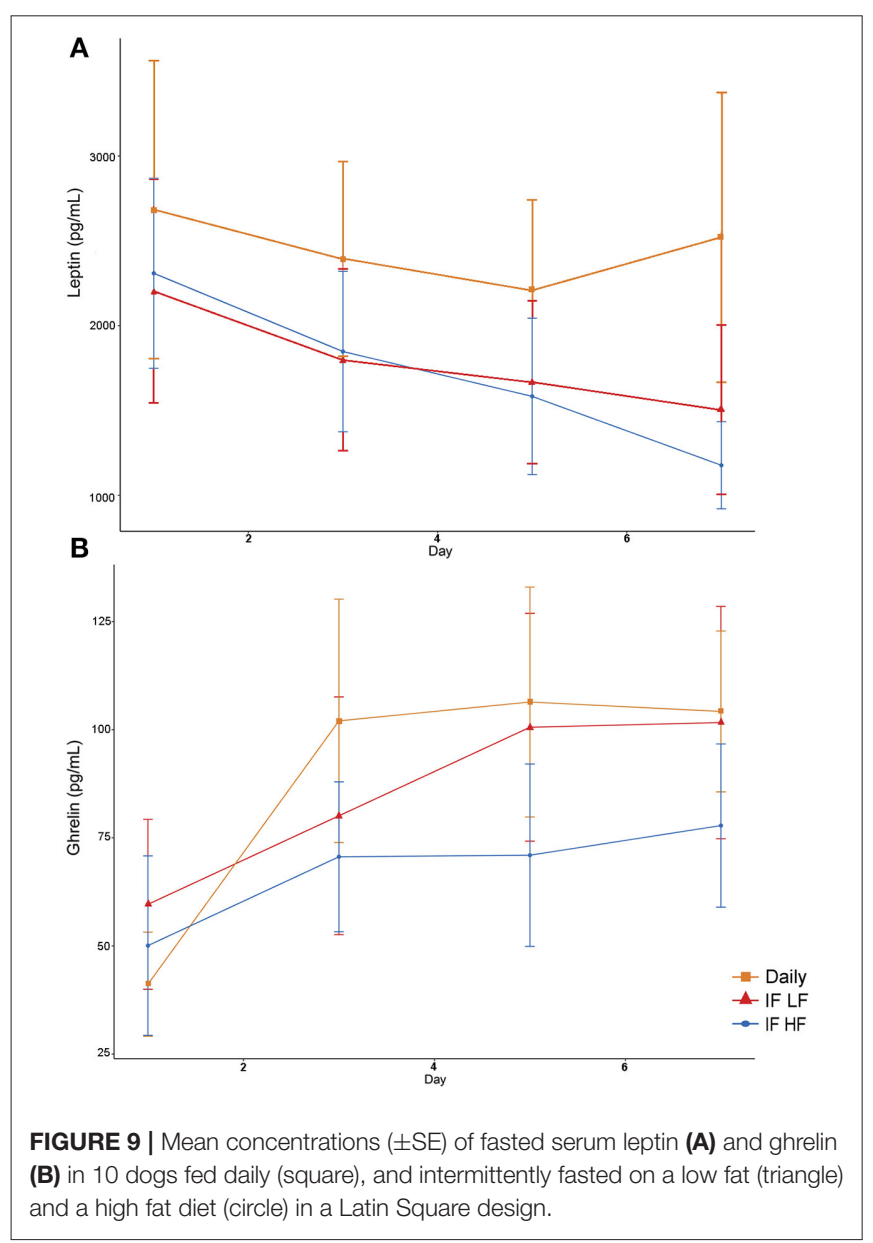

$\beta$-hydroxybutyrate in the brain and cerebral spinal fluid (CSF) is proportional to the concentration found in plasma, and increases as the duration of fasting continues $(72,79,80)$. When available, $\beta$-hydroxybutyrate is preferentially utilized over glucose, lactate and pyruvate by neurons as an energy substrate (81). So even a small increase in plasma concentrations of ketones could still provide a large contribution of energy for the brain and neurons.

In our study, all dogs had fasting blood glucose concentrations within the normal reference range, however lower values were obtained when the dogs were fasted for $48 \mathrm{~h}$ vs. $12 \mathrm{~h}$. This reflects the difference in the length of fasting rather than the macronutrient composition of the diets. Similarly in a study of dogs eating either a carbohydrate-free or high carbohydrate diet, the blood glucose concentrations were the same after a $24 \mathrm{~h}$ fast in both groups of dogs (82). The lowest concentrations of insulin were seen when the dogs were intermittently fasted on the HF diet, which indicated a decrease in insulin production and/or increase in insulin sensitivity. The HOMA insulin resistance scores were also lowest when the dogs were on this feeding regime, which is a reflection of both low fasting glucose and insulin concentrations. Both caloric restriction and a reduction in fat mass improves insulin sensitivity in overweight dogs (83-86). In our study, intermittently fasted dogs eating a HF diet lost less weight than when intermittently fasted on a LF diet, and yet had lower insulin concentrations. Therefore, it appears that intermittent fasting on a high fat diet may reduce insulin production or improve insulin sensitivity independent of weight loss.

Alanine and lactate were two gluconeogenic metabolites identified by OPLS as being different between the feeding regimes. During the early stage of fasting, proteolysis of muscle releases alanine for gluconeogenesis in hepatocytes $(87,88)$. In a study of dogs eating a carbohydrate-free diet, the turnover rate of alanine and its conversion of alanine to plasma glucose were increased after a $48 \mathrm{~h}$ fast (89). Lactate is transported by the same monocarboxylate transporters (MCTs) as ketones, and also serve as an energy source for cells, including neurons, in a fasted state $(90,91)$. Feeding a high fat diet to rats increased the expression of MCT1 by brain endothelial cells (92). Also, 

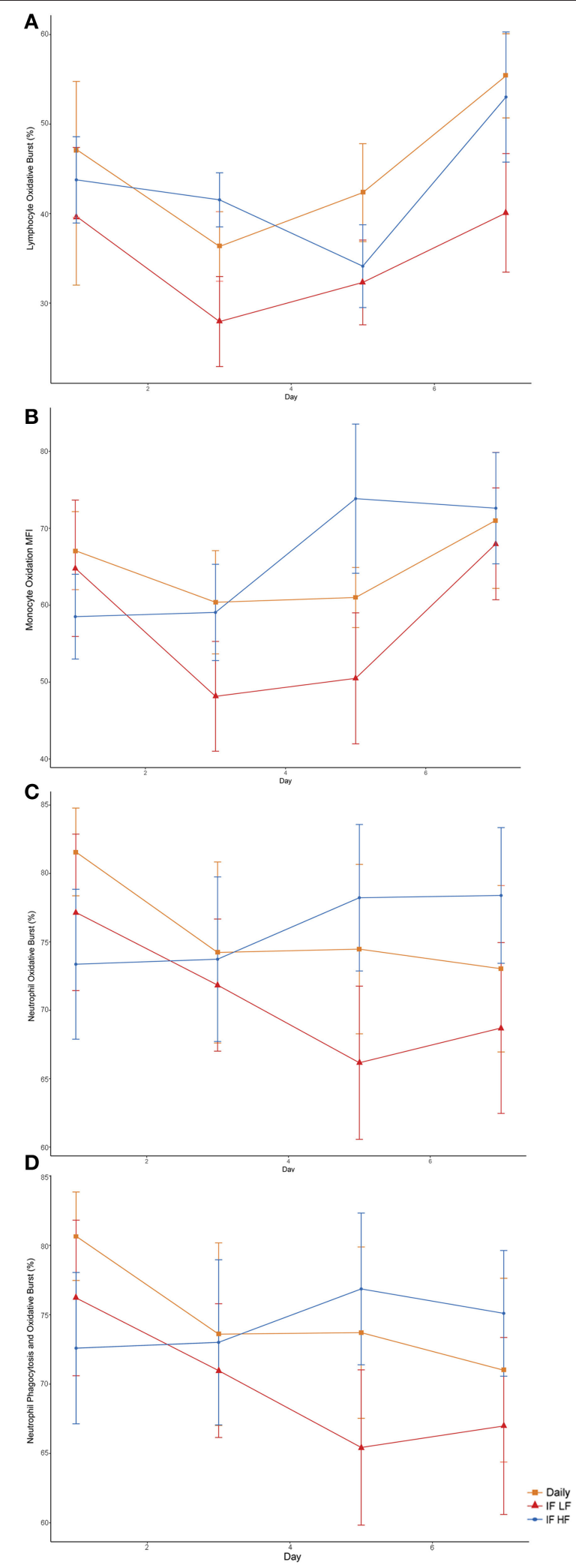

FIGURE 10 | Differences in immune parameters in 10 dogs fed daily (square), and intermittently fasted on a low fat (triangle) and a high fat diet (circle) in

(Continued)
FIGURE 10 | a Latin Square design as assessed by flow cytometry. (A) Total percentage of lymphocytes which underwent oxidative burst. (B) The mean florescence intensity of oxidative burst in monocytes which underwent both phagocytosis and oxidative burst. This is a method of quantifying the degree of oxidation. (C) Total percentage of neutrophils which underwent oxidative burst. (D) The percentage of neutrophils which underwent both phagocytosis and oxidative burst.

lactate concentrations are increased in the brain of humans fasted for 2 days (72). Thus, the reduction of both alanine and lactate in the dogs when intermittently fasted on a HF diet may be due to an increase in uptake by the liver, brain, and kidneys.

The adipokine, leptin, has many roles in the body including the activation of phagocytosis by monocytes and chemotaxis of neutrophils and oxidative radical generation (93-95). In our study, we found that leptin concentrations were lowest in the intermittently fasted dogs regardless of the fat content of the diet. Both fasting and a reduction in fat mass are known to decrease leptin production $(96,97)$. During the course of our study, the dogs lost some weight; however, there was no difference in the starting concentrations of leptin at the beginning of each study week in any of the dogs. Therefore, the reduction in leptin concentrations was the result of the fasting regime, and not fat mass loss. In addition, although leptin was not maintained during fasting by feeding a HF diet, there was no difference between the immune parameters studied in those dogs and when the dogs were fed daily. We did find a reduction in the percentage of leucocytes undergoing phagocytosis and respiratory burst when the dogs were intermittently fasted on a LF diet. This suggests that the immune changes were not leptin-mediated. The suppressive effect however was not consistent throughout all the immune parameters studied, and the clinical significance of this reduction is not known.

\section{Limitations}

Both diets used in this study were formulated to meet AAFCO requirements, and while all attempts were made to create similar nutrient profiles excluding the fat and carbohydrate content, the diets did differ from one another in some micronutrients. In addition, when the dogs were intermittently fasted on the LF diet, they lost more weight than in the other feeding regimes, indicating the dogs were in a greater catabolic state. However, an increase in proteolysis and fatty acid oxidation was not reflected by an increase in the plasma alanine and ketone concentrations of the dogs during the LF diet intermittent fasting regime. In addition, plasma ketone concentration was not associated with weight loss in this study. A washout week using the control feeding regime was performed in between each study period, and none of the outcome parameters were significantly different in the dogs at the start of each study period. Furthermore, diet order was examined in the multivariate model which did not show an effect. Our results suggest that the differences in diet profiles and greater weight loss during the LF diet intermittent fasting regime likely had a minimal effect, however, a more 
TABLE 5 | The results of the linear mixed effect models of the activity of phagocytic cells, and their respective means and standard deviations, in 10 dogs fed daily (BID), and intermittently fasted on a low fat (IF LF) and a high fat diet (LF HF) in a Latin Square design.

\begin{tabular}{|c|c|c|c|c|c|c|c|}
\hline Outcome & Diet & Mean & Standard deviation & Fixed effect & Estimate & Standard error & $P$-value \\
\hline Lymphocyte oxidation & $\mathrm{BID}$ & 45.3 & 18.4 & (Intercept) & 30.6 & 25.3 & \\
\hline \multirow[t]{2}{*}{ (\%) } & IF LF & 35.0 & 19.3 & Diet IF LF & -10.7 & 3.9 & 0.008 \\
\hline & IF HF & 43.1 & 17.1 & & & & \\
\hline Monocyte phag+/ox+ & $\mathrm{BID}$ & 64.9 & 20.0 & (Intercept) & 72.3 & 28.6 & \\
\hline \multirow[t]{2}{*}{ MFI for oxidation } & IF LF & 57.9 & 25.8 & Diet IF LF & -7.6 & 4.0 & 0.06 \\
\hline & IF HF & 66.0 & 23.5 & & & & \\
\hline Neutrophil oxidation & $\mathrm{BID}$ & 75.8 & 17.6 & (Intercept) & 73.6 & 23.3 & \\
\hline \multirow[t]{2}{*}{$(\%)$} & IF LF & 71.0 & 17.6 & Diet IF LF & -4.9 & 2.2 & 0.02 \\
\hline & IF HF & 75.9 & 16.8 & & & & \\
\hline Neutrophil phag+/ox+ & $\mathrm{BID}$ & 74.7 & 18.1 & (Intercept) & 67.9 & 23.2 & \\
\hline \multirow[t]{2}{*}{ (\%) } & IF LF & 69.9 & 17.6 & Day & -0.8 & 0.4 & 0.04 \\
\hline & IF HF & 74.4 & 16.4 & Diet IF LF & -5.0 & 2.2 & 0.03 \\
\hline
\end{tabular}

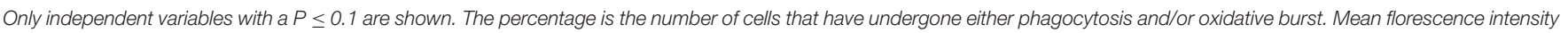
(MFI) of oxidation is proportional to the degree in which oxidation has occurred.

thorough study would be required to determine if that is indeed the case.

In our study, no ill effects were seen when the dogs were intermittently fasted on the high fat diet. Acute feeding of a high fat diet in other species can lead to an increase in circulating pro-inflammatory cytokines such as interleukin $1 \beta$ and tumor necrosis- $\alpha$, but this has not been shown consistently (98). Interestingly, an intermittent fasting regime has been shown to ameliorate the expression of proinflammation-related genes in hepatocytes during long-term high-fat feeding in mice (99). The effects of intermittent fasting on markers of inflammation during high fat feeding in dogs is not currently known. We did not measure inflammatory cytokines in our study, however future studies may wish to do so. Furthermore, a difference in immunity between the feeding regimes was apparent only when the dogs were intermittently fasted on the LF diet. The significance of this immune effect is not known, but there may be a greater implication of this in a clinical setting.

To promote ketone formation, coconut oil was used in the HF diet as a rich source of medium-chain triglycerides. However, the main medium-chain triglyceride constituent in coconut oil is dodecanoic acid (lauric acid, C12), with decanoic acid (capric acid, C10) and octanoic acid (caprylic acid, C8) as the great remainder (100). When given in equal amounts, intake of decanoic acid and octanoic acid leads to a greater ketone production postprandially then dodecanoic acid (101, 102). Thus, to increase the effect of medium-chain triglycerides on ketogenesis, a concentrated oil with a higher quantity of decanoic and octanoic acid can be given instead of coconut oil.

The homeostasis model assessment (HOMA) was developed to provide a measure of peripheral insulin resistance from fasting glucose and insulin. The scores correlate well with a euglycemic clamp model in humans, and has been used to detect improvements in insulin sensitivity with weight loss and fasting in humans (103-105). In our study, dogs intermittently fasted on a HF diet had the lowest HOMA score compared to when they were fed daily or intermittently fasted on the LF diet. However, HOMA has been found to be variably reliable in companion animals in detecting insulin resistance (106-108). So while we found a difference with HOMA scores in the different feeding regimes, any interpretation in peripheral insulin sensitivity should be confirmed using a euglycemic clamp.

\section{CONCLUSION}

In this study, we found that fasting for up to $48 \mathrm{~h}$ in healthy dogs does not cause immunosuppression, and that fasting on a high fat diet enriched with medium-chain triglycerides promoted a greater plasma ketone concentration than when the dogs were fasted after eating a low fat diet. However, the concentrations obtained in dogs are significantly less than what is reported in other species fasted for a similar period of time. Therefore, a ketone kinetics study is required to gain a more comprehensive understanding of the flux of ketones in dogs while fasting for varying durations, and whether this feeding regime could be feasible in hospitalized dogs recovering from neuronal injury. In addition, dogs intermittently fasted on a low fat diet consumed fewer calories and lost more weight than when fed the high fat diet. Therefore, any practical application of this type of feeding regime would require modification of the diet itself (e.g., increase the energy density of the diet to reduce the volume and gut fill) and/or reducing the number of days or length of fasting. Ultimately, while we showed the possibility of this type of feeding regime to be feasible and to produce ketones without ill effect in healthy dogs, its application in hospitalized dogs remains to be determined.

\section{DATA AVAILABILITY STATEMENT}

The datasets generated for this study are available on request to the corresponding author. 


\section{ETHICS STATEMENT}

The animal study was reviewed and approved by Massey University Animal Ethics Committee (MUAEC \#16/130).

\section{AUTHOR CONTRIBUTIONS}

YL and NC conceptualized and designed the study. YL was the primary researcher, with assistance from NC. YL organized data collection, completed laboratory preparation of blood samples, performed the statistical analysis, and wrote the first draft of the manuscript. AH supervised the immunological assays. PE performed the NMR analysis. AG reviewed the study design and

\section{REFERENCES}

1. Remillard RL, Darden DE, Michel KE, Marks SL, Buffington CA, Bunnell PR. An investigation of the relationship between caloric intake and outcome in hospitalized dogs. Vet Ther Res Appl Vet Med. (2001) 2:301-10.

2. Hiesmayr M, Schindler K, Pernicka E, Schuh C, Schoeniger-Hekele A, Bauer P, et al. Decreased food intake is a risk factor for mortality in hospitalised patients: the NutritionDay survey 2006. Clin Nutr. (2009) 28:484-91. doi: 10.1016/j.clnu.2009.05.013

3. Lim SL, Ong KCB, Chan YH, Loke WC, Ferguson M, Daniels L. Malnutrition and its impact on cost of hospitalization, length of stay, readmission and 3year mortality. Clin Nutr. (2012) 31:345-50. doi: 10.1016/j.clnu.2011.11.001

4. Agarwal E, Ferguson M, Banks M, Batterham M, Bauer J, Capra S, et al. Malnutrition and poor food intake are associated with prolonged hospital stay, frequent readmissions, and greater in-hospital mortality: results from the Nutrition Care Day Survey 2010. Clin Nutr. (2013) 32:73745. doi: 10.1016/j.clnu.2012.11.021

5. Klein CJ, Stanek GS, Wiles CE. Overfeeding macronutrients to critically ill adults: metabolic complications. J Am Diet Assoc. (1998) 98:795-806. doi: 10.1016/S0002-8223(98)00179-5

6. Alaedeen DI, Walsh MC, Chwals WJ. Total parenteral nutritionassociated hyperglycemia correlates with prolonged mechanical ventilation and hospital stay in septic infants. J Pediatr Surg. (2006) 41:239-44. doi: 10.1016/j.jpedsurg.2005.10.045

7. Reid C. Frequency of under- and overfeeding in mechanically ventilated ICU patients: causes and possible consequences. J Hum Nutr Diet. (2006) 19:13-22. doi: 10.1111/j.1365-277X.2006.00661.x

8. Nishikawa T, Edelstein D, Du XL, Yamagishi SI, Matsumura T, Kaneda $\mathrm{Y}$, et al. Normalizing mitochondrial superoxide production blocks three pathways of hyperglycaemic damage. Nature. (2000) 404:787-90. doi: $10.1038 / 35008121$

9. Diabetes Control and Complications Trial Research Group. The effect of intensive treatment of diabetes on the development and progression of longterm complications in insulin-dependent diabetes mellitus. $N$ Engl J Med. (1993) 329:997-86. doi: 10.1056/NEJM199309303291401

10. Gore DC, Chinkes D, Heggers J, Herndon DN, Wolf SE. Association of hyperglycemia with increased mortality after severe burn injury. J Trauma Acute Care Surg. (2001) 51:540-4. doi: 10.1097/00005373-200109000-00021

11. Esposito K, Nappo F, Marfella R, Giugliano G, Giugliano F, Ciotola $\mathrm{M}$, et al. Inflammatory cytokine concentrations are acutely increased by hyperglycemia in humans: role of oxidative stress. Circulation. (2002) 106:2067-72. doi: 10.1161/01.CIR.0000034509.14906.AE

12. Ceriello A, Quagliaro L, Piconi L, Assaloni R, Da Ros R, Maier A, et al. Effect of postprandial hypertriglyceridemia and hyperglycemia on circulating adhesion molecules and oxidative stress generation and the possible role of simvastatin treatment. Diabetes. (2004) 53:701-10. doi: 10.2337/diabetes.53.3.701

13. Jellinger PS. Metabolic consequences of hyperglycemia and insulin resistance. Insulin. (2009) 4:2-14. doi: 10.1016/S1557-0843(09)80003-1

14. Van den Berghe G, Wouters P, Weekers F, Verwaest C, Bruyninckx F, Schetz $\mathrm{M}$, et al. Intensive insulin therapy in critically ill patients. $N$ Engl J Med. (2001) 345:1359-67. doi: 10.1056/NEJMoa011300 statistical analysis. TW contributed by the reading and revision of the manuscript. All authors contributed to manuscript revision and approved the submitted version.

\section{FUNDING}

This work described in this manuscript was funded internally.

\section{ACKNOWLEDGMENTS}

The authors would like to thank Brittnee Southland for her assistance with making and distributing the diets and blood sample collection.

15. Rogozina OP, Bonorden MJL, Seppanen CN, Grande JP, Cleary MP. Effect of chronic and intermittent calorie restriction on serum adiponectin and leptin and mammary tumorigenesis. Cancer Prev Res. (2011) 4:568-81. doi: 10.1158/1940-6207.CAPR-10-0140

16. Horne BD, Muhlestein JB, Anderson JL. Health effects of intermittent fasting: hormesis or harm? A systematic review. Am J Clin Nutr. (2015) 102:464-70. doi: 10.3945/ajcn.115.109553

17. Faris MA, Kacimi S, Al-Kurd RA, Fararjeh MA, Bustanji YK, Mohammad $\mathrm{MK}$, et al. Intermittent fasting during Ramadan attenuates proinflammatory cytokines and immune cells in healthy subjects. Nutr Res. (2012) 32:947-55. doi: 10.1016/j.nutres.2012.06.021

18. Tikoo K, Tripathi DN, Kabra DG, Sharma V, Gaikwad AB. Intermittent fasting prevents the progression of type I diabetic nephropathy in rats and changes the expression of Sir2 and p53. FEBS Lett. (2007) 581:1071-8. doi: 10.1016/j.febslet.2007.02.006

19. Ahmet I, Wan R, Mattson MP, Lakatta EG, Talan M. Cardioprotection by intermittent fasting in rats. Circulation. (2005) 112:3115-21. doi: 10.1161/CIRCULATIONAHA.105.563817

20. Katare RG, Kakinuma Y, Arikawa M, Yamasaki F, Sato T. Chronic intermittent fasting improves the survival following large myocardial ischemia by activation of BDNF/VEGF/PI3K signaling pathway. J Mol Cell Cardiol. (2009) 46:405-12. doi: 10.1016/j.yjmcc.2008.10.027

21. Anson RM, Guo Z, de Cabo R, Iyun T, Rios M, Hagepanos A, et al. Intermittent fasting dissociates beneficial effects of dietary restriction on glucose metabolism and neuronal resistance to injury from calorie intake. Proc Natl Acad Sci USA. (2003) 100:6216-20. doi: 10.1073/pnas.10357 20100

22. Plunet WT, Streijger F, Lam CK, Lee JHT, Liu J, Tetzlaff W. Dietary restriction started after spinal cord injury improves functional recovery. Exp Neurol. (2008) 213:28-35. doi: 10.1016/j.expneurol.2008.04.011

23. Jeong M, Plunet W, Streijger F, Lee JHT, Plemel JR, Park S, et al. Intermittent fasting improves functional recovery after rat thoracic contusion spinal cord injury. J Neurotrauma. (2011) 28:479-92. doi: 10.1089/neu.2010.1609

24. Arum O, Saleh JK, Boparai RK, Kopchick JJ, Khardori RK, Bartke A. Preservation of blood glucose homeostasis in slow-senescing somatotrophism-deficient mice subjected to intermittent fasting begun at middle or old age. Age. (2014) 36:1263-90. doi: 10.1007/s11357-0149695-3

25. Mafauzy M, Mohammed WB, Anum MY, Zulkifli A, Ruhani AH. A study of the fasting diabetic patients during the month of Ramadan. Med J Malaysia. (1990) 45:14-7.

26. Derde S, Vanhorebeek I, Güiza F, Derese I, Gunst J, Fahrenkrog B, et al. Early parenteral nutrition evokes a phenotype of autophagy deficiency in liver and skeletal muscle of critically ill rabbits. Endocrinology. (2012) 153:2267-76. doi: 10.1210/en.2011-2068

27. Alirezaei M, Kemball CC, Flynn CT, Wood MR, Whitton JL, Kiosses WB. Short-term fasting induces profound neuronal autophagy. Autophagy. (2010) 6:702-10. doi: 10.4161/auto.6.6.12376

28. Descamps O, Riondel J, Ducros V, Roussel AM. Mitochondrial production of reactive oxygen species and incidence of age-associated lymphoma in OF1 mice: effect of alternate-day fasting. Mech Ageing Dev. (2005) 126:1185-91. doi: 10.1016/j.mad.2005.06.007 
29. Yin J, Han P, Tang Z, Liu Q, Shi J. Sirtuin 3 mediates neuroprotection of ketones against ischemic stroke. J Cereb Blood Flow Metab. (2015) 35:1783-9. doi: $10.1038 /$ jcbfm.2015.123

30. Julio-Amilpas A, Montiel T, Soto-Tinoco E, Gerónimo-Olvera C, Massieu L. Protection of hypoglycemia-induced neuronal death by $\beta$-hydroxybutyrate involves the preservation of energy levels and decreased production of reactive oxygen species. J Cereb Blood Flow Metab. (2015) 35:851-60. doi: $10.1038 /$ jcbfm.2015.1

31. Moon M, Kim HG, Hwang L, Seo J-H, Kim S, Hwang S, et al. Neuroprotective effect of ghrelin in the 1-methyl-4-phenyl1,2,3,6-tetrahydropyridine mouse model of Parkinson's disease by blocking microglial activation. Neurotox Res. (2009) 15:332-47. doi: 10.1007/s12640-009-9037-X

32. Miao Y, Xia Q, Hou Z, Zheng Y, Pan H, Zhu S. Ghrelin protects cortical neuron against focal ischemia/reperfusion in rats. Biochem Biophys Res Commun. (2007) 359:795-800. doi: 10.1016/j.bbrc.2007.05.192

33. Briet F, Twomey C, Jeejeebhoy KN. Effect of malnutrition and shortterm refeeding on peripheral blood mononuclear cell mitochondrial complex I activity in humans. Am J Clin Nutr. (2003) 77:1304-11. doi: 10.1093/ajen/77.5.1304

34. Fujita $Y$, Yanagida $H$, Mimori T, Jin Z-X, Sakai T, Kawanami $\mathrm{T}$, et al. Prevention of fasting-mediated bone marrow atrophy by leptin administration. Cell Immunol. (2012) 273:52-8. doi: 10.1016/j.cellimm.2011.11.007

35. La Cava A, Matarese G. The weight of leptin in immunity. Nat Rev Immunol. (2004) 4:371-9. doi: 10.1038/nri1350

36. Xu D-L, Wang D-H. Fasting suppresses T cell-mediated immunity in female Mongolian gerbils (Meriones unguiculatus). Comp Biochem Physiol A Mol Integr Physiol. (2010) 155:25-33. doi: 10.1016/j.cbpa.2009.09.003

37. Ben-Nathan B, Drabkin N, Heller D. The effect of starvation on the immune response of chickens. Avian Dis. (1980) 25:214-7. doi: 10.2307/ 1589845

38. Lord GM, Matarese G, Howard JK, Baker RJ, Bloom SR, Lechler RI. Leptin modulates the $\mathrm{T}$-cell immune response and reverses starvation-induced immunosuppression. Nature. (1998) 394:897-901. doi: 10.1038/29795

39. Loffreda S, Yang SQ, Lin HZ, Karp CL, Brengman ML, Wang DJ, et al. Leptin regulates proinflammatory immune responses. FASEB J. (1997) 12:57-65. doi: 10.1096/fasebj.12.1.57

40. Deng P, Jones JC, Swanson KS. Effects of dietary macronutrient composition on the fasted plasma metabolome of healthy adult cats. Metabolomics. (2014) 10:638-50. doi: 10.1007/s11306-013-0617-7

41. Tisdale MJ, Brennan RA, Fearon KC. Reduction of weight loss and tumour size in a cachexia model by a high fat diet. Br J Cancer. (1987) 56:39-43. doi: 10.1038/bjc.1987.149

42. Grancher D, Jean-Blain C, Frey A, Schirardin H, Bach A. Studies on the tolerance of medium chain triglycerides in dogs. J Parenter Enter Nutr. (1987) 11:280-6. doi: 10.1177/0148607187011003280

43. Cotter R, Taylor CA, Johnson R, Rowe WB. A metabolic comparison of a pure long-chain triglyceride lipid emulsion (LCT) and various mediumchain triglyceride (MCT)-LCT combination emulsions in dogs. Am J Clin Nutr. (1987) 45:927-39. doi: 10.1093/ajcn/45.5.927

44. Yeh YY, Zee P. Relation of ketosis to metabolic changes induced by acute medium-chain triglyceride feeding in rats. J Nutr. (1976) 106:58-67. doi: $10.1093 /$ jn/106.1.58

45. Seaton TB, Welle SL, Warenko MK, Campbell RG. Thermic effect of medium-chain and long-chain triglycerides in man. Am J Clin Nutr. (1986) 44:630-4. doi: 10.1093/ajcn/44.5.630

46. Ingle DL, Driedger A, Traul KA, Nakhasi DK. Dietary energy value of medium-chain triglycerides. J Food Sci. (1999) 64:960-3. doi: 10.1111/j.1365-2621.1999.tb12259.x

47. Kang MH, Kim DH, Jeong IS, Choi GC, Park HM. Evaluation of four portable blood glucose meters in diabetic and non-diabetic dogs and cats. Vet Q. (2016) 36:2-9. doi: 10.1080/01652176.2015.1092617

48. Nagana Gowda GA, Gowda YN, Raftery D. Expanding the limits of human blood metabolite quantitation using NMR spectroscopy. Anal Chem. (2015) 87:706-15. doi: 10.1021/ac503651e

49. Viana KF, Aguiar-Soares RDO, Roatt BM, Resende LA, Da SilveiraLemos D, Corrêa-Oliveira R, et al. Analysis using canine peripheral blood for establishing in vitro conditions for monocyte differentiation into macrophages for Leishmania chagasi infection and T-cell subset purification. Vet Parasitol. (2013) 198:62-71. doi: 10.1016/j.vetpar.2013.08.014

50. Kampen AH, Tollersrud T, Lund A. Flow cytometric measurement of neutrophil respiratory burst in whole bovine blood using live Staphylococcus aureus. J Immunol Methods. (2004) 289:47-55. doi: 10.1016/j.jim.2004.03.008

51. Lehnert B. BlandAltmanLeh: Plots (Slightly Extended) Bland-Altman Plots. R package version 0.3.1 (2015). Available online at: https://CRAN.R-project. org/package $=$ BlandAltmanLeh

52. Bland JM, Altman DG. Agreement between methods of measurement with multiple observations per individual. J Biopharm Stat. (2007) 17:571-82. doi: 10.1080/10543400701329422

53. Bates D, Maechler M, Bolker B, Walker S. Fitting linear mixed-effects models using lme4. J Stat Softw. (2015) 67:1-48. doi: 10.18637/jss.v067.i01

54. R Core Team (2019). R: A Language and Environment for Statistical Computing. Vienna: R Foundation for Statistical Computing. Available online at: https://www.R-project.org/

55. Ganesh S, Cave V. P-values, p-values everywhere!. N Z Vet J. (2018) 66:55-6. doi: 10.1080/00480169.2018.1415604

56. West D, York B. Dietary fat, genetic predisposition, and obesity: lessons from animal models. Am J Clin Nutr. (1998) 67(Suppl. 3):505S-12S. doi: 10.1093/ajen/67.3.505S

57. Romsos DR, Hornshuh MJ, Leveille GA. Influence of dietary fat and carbohydrate on food intake, body weight and body fat of adult dogs. Proc Soc Exp Biol Med. (1978) 157:278-81. doi: 10.3181/00379727-157-40037

58. Hess RS, Saunders HM, Van Winkle TJ, Shofer FS, Washabau RJ. Clinical, clinicopathologic, radiographic, and ultrasonographic abnormalities in dogs with fatal acute pancreatitis: 70 cases (1986-1995). J Am Vet Med Assoc. (1998) 213:665-70.

59. Brian Haig TH, Haig THB. Experimental pancreatitis intensified by a high fat diet. Surg Gynecol Obstet. (1970) 131:914-8.

60. Lindsay S, Entenman C, Chaikoff IL. Pancreatitis accompanying hepatic disease in dogs fed a high fat, low protein diet. Arch Pathol. (1948) 45:635-8.

61. Lem KY, Fosgate GT, Norby B, Steiner JM. Associations between dietary factors and pancreatitis in dogs. J Am Vet Med Assoc. (2008) 233:1425-31. doi: 10.2460/javma.233.9.1425

62. James FE, Mansfield CS, Steiner JM, Williams DA, Robertson ID. Pancreatic response in healthy dogs fed diets of various fat compositions. Am J Vet Res. (2009) 70:614-8. doi: 10.2460/ajvr.70.5.614

63. Orr NWM. The feeding of sledge dogs on Antarctic expeditions. Br J Nutr. (1966) 20:1-12. doi: 10.1079/BJN19660003

64. Downey RL, Kronfeld DS, Banta CA. Diet of beagles affects stamina. J Am Anim Hosp Assoc. (1980) 16:273-7.

65. Reynolds AJ, Fuhrer L, Dunlap HL, Finke MD, Kallfelz FA. Lipid metabolite responses to diet and training in sled dogs. J Nutr. (1994) 124:2754S-9S. doi: 10.1093/jn/124.suppl_12.2754S

66. Falecka-Wieczorek I, Kaciuba-USciłko H. Metabolic and hormonal responses to prolonged physical exercise in dogs after a single fatenriched meal. Eur J Appl Physiol Occup Physiol. (1984) 53:267-73. doi: 10.1007/BF00776601

67. Wyatt HT. Further experiments on the nutrition of sledge dogs. Br J Nutr. (1963) 17:273-9. doi: 10.1079/BJN19630030

68. Reynolds AJ, Dunlap HL, Finke M, Kallfelz FA, Fuhrer L. Effect of diet and training on muscle glycogen storage and utilization in sled dogs. J Appl Physiol. (1995) 79:1601-7. doi: 10.1152/jappl.1995.79.5.1601

69. Suzuki M, Suzuki M, Kitamura Y, Mori S, Sato K, Dohi S, et al. Betahydroxybutyrate, a cerebral function improving agent, protects rat brain against ischemic damage caused by permanent and transient focal cerebral ischemia. Jpn J Pharmacol. (2002) 89:36-43. doi: 10.1254/jjp.89.36

70. Massieu L, Haces ML, Montiel T, Hernández-Fonseca K. Acetoacetate protects hippocampal neurons against glutamate-mediated neuronal damage during glycolysis inhibition. Neuroscience. (2003) 120:365-78. doi: 10.1016/S0306-4522(03)00266-5

71. Haces ML, Hernández-Fonseca K, Medina-Campos ON, Montiel T, Pedraza-Chaverri J, Massieu L. Antioxidant capacity contributes to protection of ketone bodies against oxidative damage induced during hypoglycemic conditions. Exp Neurol. (2008) 211:85-96. doi: 10.1016/j.expneurol.2007.12.029

72. Pan JW, Rothman TL, Behar KL, Stein DT, Hetherington HP. Human brain beta-hydroxybutyrate and lactate increase in 
fasting-induced ketosis. J Cereb Blood Flow Metab. (2000) 20:1502-7. doi: 10.1097/00004647-200010000-00012

73. Hawkins RA, Williamson DH, Krebs HA. Ketone-body utilization by adult and suckling rat brain in vivo. Biochem J. (1971) 122:13-8. doi: $10.1042 /$ bj 1220013

74. De Bruijne JJ, van den Brom WE. The effect of long-term fasting on ketone body metabolism in the dog. Comp Biochem Physiol. (1986) 83:391-5. doi: 10.1016/0305-0491(86)90386-X

75. Keller U, Shulman G. Effect of glucagon on hepatic fatty acid oxidation and ketogenesis in conscious dogs. Am J Physiol. (1979) 237:E121-9. doi: 10.1152/ajpendo.1979.237.2.E121

76. Crandall LA. A comparison of ketosis in man and dog. J Biol Chem. (1940) 138:123-9.

77. Keller U, Cherrington AD, Liljenquist JE. Ketone body turnover and net hepatic ketone production in fasted and diabetic dogs. Am J Physiol. (1978) 235:E238-47. doi: 10.1152/ajpendo.1978.235.2.E238

78. Reichard GA Jr, Paul P, Bortz WM. Ketone-body production and oxidation in fasting obese humans. J Clin Invest. (1974) 53:508-15. doi: 10.1172/JCI107584

79. Wiener R, Hirsch HJ, Spitzer JJ. Cerebral extraction of ketones and their penetration into CSF in the dog. Am J Physiol. (1971) 220:1542-6. doi: 10.1152/ajplegacy.1971.220.5.1542

80. Lamers KJ, Doesburg WH, Gabreëls FJ, Romsom AC, Lemmens WA, Wevers RA, et al. CSF concentration and CSF/blood ratio of fuel related components in children after prolonged fasting. Clin Chim Acta. (1987) 167:135-45. doi: 10.1016/0009-8981(87)90366-4

81. Valente-Silva P, Lemos C, Köfalvi A, Cunha RA, Jones JG. Ketone bodies effectively compete with glucose for neuronal acetyl-CoA generation in rat hippocampal slices. NMR Biomed. (2015) 28:1111-6. doi: 10.1002/nbm.3355

82. Belo PS, Romsos DR, Leveille GA. Influence of diet on glucose tolerance, on the rate of glucose utilization and on gluconeogenic enzyme activities in the dog. J Nutr. (1976) 106:1465-74. doi: 10.1093/jn/106.10.1465

83. Kahn SE, Hull RL, Utzschneider KM. Mechanisms linking obesity to insulin resistance and type 2 diabetes. Nature. (2006) 444:840-6. doi: 10.1038/nature 05482

84. Blanchard GG, Nguyen P, Gayet C, Leriche I, Siliart B, Paragon B-M. Rapid weight loss with a high-protein low-energy diet allows the recovery of ideal body composition and insulin sensitivity in obese dogs. J Nutr. (2004) 134(Suppl. 8):2148S-50S. doi: 10.1093/jn/134.8.2148S

85. German AJ, Hervera M, Hunter L, Holden SL, Morris PJ, Biourge V, et al. Improvement in insulin resistance and reduction in plasma inflammatory adipokines after weight loss in obese dogs. Domest Anim Endocrinol. (2009) 37:214-26. doi: 10.1016/j.domaniend.2009.07.001

86. Adolphe JL, Silver TI, Childs H, Drew MD, Weber LP. Short-term obesity results in detrimental metabolic and cardiovascular changes that may not be reversed with weight loss in an obese dog model. Br J Nutr. (2014) 112:647-56. doi: 10.1017/S0007114514001214

87. Blackshear PJ, Holloway PAH, Alberti KGMM. The effects of starvation and insulin on the release of gluconeogenic substrates from the extra-splanchnic tissues in vivo. FEBS Lett. (1974) 48:310-3. doi: 10.1016/0014-5793(74)80493-X

88. Saudek CD, Felig P. The metabolic events of starvation. Am J Med. (1976) 60:117-26. doi: 10.1016/0002-9343(76)90540-4

89. Belo PS, Romsos DR, Leveille GA. Influence of diet on lactate, alanine and serine turnover and incorporation into glucose in the dog. J Nutr. (1977) 107:397-403. doi: 10.1093/jn/107.3.397

90. Gjedde A, Crone C. Induction processes in blood-brain transfer of ketone bodies during starvation. Am J Physiol. (1975) 229:1165-9. doi: 10.1152/ajplegacy.1975.229.5.1165

91. Bouzier-Sore AK, Voisin P, Canioni P, Magistretti PJ, Pellerin L. Lactate is a preferential oxidative energy substrate over glucose for neurons in culture. J Cereb Blood Flow Metab. (2003) 23:1298-306. doi: 10.1097/01.WCB.0000091761.61714.25

92. Leino RL, Gerhart DZ, Duelli R, Enerson BE, Drewes LR. Diet-induced ketosis increases monocarboxylate transporter (MCT1) levels in rat brain. Neurochem Int. (2001) 38:519-27. doi: 10.1016/S0197-0186(00)00102-9

93. Dixit VD, Mielenz M, Taub DD, Parvizi N. Leptin induces growth hormone secretion from peripheral blood mononuclear cells via a protein kinase Cand nitric oxide-dependent mechanism. Endocrinology. (2003) 144:5595603. doi: 10.1210/en.2003-0600
94. Caldefie-Chezet F, Poulin A, Vasson MP. Leptin regulates functional capacities of polymorphonuclear neutrophils. Free Radic Res. (2003) 37:80914. doi: 10.1080/1071576031000097526

95. Lukacs NW, Peters-Golden M, Gottschalk A, Phare SM, Mancuso P, Huffnagle GB. Leptin-deficient mice exhibit impaired host defense in gram-negative pneumonia. J Immunol. (2014) 168:4018-24. doi: 10.4049/jimmunol.168.8.4018

96. Howard JK, Lord GM, Matarese G, Vendetti S, Ghatei MA, Ritter MA, et al. Leptin protects mice from starvation-induced lymphoid atrophy and increases thymic cellularity in ob/ob mice. J Clin Invest. (1999) 104:1051-9. doi: 10.1172/JCI6762

97. Weigle DS, Duell PB, Connor WE, Steiner RA, Soules MR, Kuijper JL. Effect of fasting, refeeding, and dietary-fat restriction on plasma leptin levels. J Clin Endocrinol Metab. (1997) 82:561-5. doi: 10.1210/jc.82.2.561

98. Herieka M, Erridge C. High-fat meal induced postprandial inflammation. Mol Nutr Food Res. (2014) 58:136-46. doi: 10.1002/mnfr.2013 00104

99. Yang W, Cao M, Mao X, Wei X, Li X, Chen G, et al. Alternateday fasting protects the livers of mice against high-fat diet-induced inflammation associated with the suppression of Toll-like receptor 4/nuclear factor $\kappa$ B signaling. Nutr Res. (2016) 36:586-93. doi: 10.1016/j.nutres.2016. 02.001

100. Bhatnagar AS, Prasanth Kumar PK, Hemavathy J, Gopala Krishna AG. Fatty acid composition, oxidative stability, and radical scavenging activity of vegetable oil blends with coconut oil. J Am Oil Chem Soc. (2009) 86:991-9. doi: 10.1007/s11746-009-1435-y

101. Castellano C-A, Pierotti T, St-Pierre V, Cunnane SC, Vandenberghe C, Fortier M. Tricaprylin alone increases plasma ketone response more than coconut oil or other medium-chain triglycerides: an acute crossover study in healthy adults. Curr Dev Nutr. (2017) 1:e000257. doi: $10.3945 / \mathrm{cdn} .116 .000257$

102. St-Pierre V, Vandenberghe C, Lowry C-M, Fortier M, Castellano C-A, Wagner R, et al. Plasma ketone and medium chain fatty acid response in humans consuming different medium chain triglycerides during a Metabolic Study Day. Front Nutr. (2019) 6:1-8. doi: 10.3389/fnut.2019.00046

103. Matthews DR, Hosker JP, Rudenski AS, Naylor BA, Treacher DF, Turner RC. Homeostasis model assessment: insulin resistance and $\beta$-cell function from fasting plasma glucose and insulin concentrations in man. Diabetologia. (1985) 28:412-9. doi: 10.1007/BF00280883

104. Harvie MN, Pegington M, Mattson MP, Frystyk J, Dillon B, Evans G, et al. The effects of intermittent or continuous energy restriction on weight loss and metabolic disease risk markers: a randomized trial in young overweight women. Int J Obes. (2011) 35:714-27. doi: 10.1038/ijo.2010.171

105. Klempel MC, Kroeger CM, Bhutani S, Trepanowski JF, Varady KA. Intermittent fasting combined with calorie restriction is effective for weight loss and cardio-protection in obese women. Nutr J. (2012) 11:1-9. doi: 10.1186/1475-2891-11-98

106. Ader M, Stefanovski D, Richey JM, Kim SP, Kolka CM, Ionut V, et al. Failure of homeostatic model assessment of insulin resistance to detect marked diet-induced insulin resistance in dogs. Diabetes. (2014) 63:1914-9. doi: $10.2337 / \mathrm{db} 13-1215$

107. Appleton DJ, Rand JS, Sunvold GD. Basal plasma insulin and homeostasis model assessment (HOMA) are indicators of insulin sensitivity in cats. $J$ Feline Med Surg. (2005) 7:183-93. doi: 10.1016/j.jfms.2004.12.002

108. Slingerland LI, Robben JH, Van Haeften TW, Kooistra HS, Rijnberk A. Insulin sensitivity and $\beta$-cell function in healthy cats: assessment with the use of the hyperglycemic glucose clamp. Horm Metab Res. (2007) 39:341-6. doi: 10.1055/s-2007-976541

Conflict of Interest: The authors declare that the research was conducted in the absence of any commercial or financial relationships that could be construed as a potential conflict of interest.

Copyright $\odot 2020$ Leung, Cave, Heiser, Edwards, Godfrey and Wester. This is an open-access article distributed under the terms of the Creative Commons Attribution License (CC BY). The use, distribution or reproduction in other forums is permitted, provided the original author(s) and the copyright owner(s) are credited and that the original publication in this journal is cited, in accordance with accepted academic practice. No use, distribution or reproduction is permitted which does not comply with these terms. 